\title{
Sosyobilimsel bir Konu Olan GDO Konusunda Öğrenci Gözüyle Diyalojik Öğretim*
}

\author{
Esra UÇAK*, Ayşe SAVRAN GENCER**, Arife SEVIŞ***, Sibel USTA****
}

- Geliş Tarihi: 28.11.2021 • Kabul Tarihi: 03.02.2022 • Çevrimiçi Yayın Tarihi: 03.02.2022

\section{$\ddot{\mathbf{O} z}$}

Diyalojik öğretimin yapılabilir ve yararlı olduğuna dair çalışmalar olmasına rağmen, araştırmalar öğretmen tarafından tartışmaların yönlendirildiği otoriter sınıf söyleminin hakim olma eğiliminde olduğunu ortaya koymaktadır. Çalışmada, diyalojik bir öğrenme ortamında öğrencilerin kendilerini ele alınan konu ile bağlantılı olarak nasıl konumlandırdıkları incelenmiştir. Bunun için, oldukça otoriter söylemleri olduğu tespit edilen bir fen öğretmeninden, 12 hafta boyunca diyalojik öğretim ve iletişimsel yaklaşım üzerine aldığı eğitimlerden sonra sosyobilimsel bir konu olan GDO konusunda diyalojik bir ders tasarısı oluşturması istenmiştir. Uygulama sonrasında altı öğrenci ile işlenen dersler ile ilgili yarı yapılandırılmış görüşmeler yapılmıştır, ayrıca aynı öğrencilerden diyalojik işlenen dersler ile daha önce işledikleri fen derslerini işleniş biçimi açısından resim çizerek karşılaştırmaları ve çizdikleri resimleri açıklamaları istenmiştir. Araştırmanın bulgularında; diyalojik öğretimde öğretmen ve öğrenci rolü, sınıf normları, öğrenme ortamı, öğrenci özellikleri ve öğrenci-öğrenci etkileşimine yönelik oluşturulan temalara ilişkin öğrenci görüşleri açığa çıkarılmış ve öğrenci resimleri ile diyalojik öğrenme ortamı yorumlanmıştır. Öğrencilerin görüşme bulguları incelendiğinde; özellikle sınıf içi konumlara ilişkin görüşmeye katılan tüm öğrenciler öğretmenlerini kutup yıldızına yani rehbere benzetmişler, kendilerini ise fikirlerini özgürce söyleyip savunan, araştıran, derse aktif katılan katılımcılar olarak konumlandırmışlardır. Görüşmeye katılan öğrencilerin çizimleri ve yorumları incelendiğinde ise öğretmenin önceki fen derslerine göre diyalojik olarak işlediği derslerinde öğrencilerin fikir ve görüşlerini alarak derslere daha fazla öğrencinin aktif katılımının olduğu tespit edilmiştir.

Anahtar sözcükler: diyalojik öğretim, sosyobilimsel konular, GDO, fen bilimleri

\section{Atıf}

Uçak, E., Gencer, A.S., Seviş, A. ve Usta, S. (2022). Sosyobilimsel bir konu olan GDO konusunda öğrenci gözüyle diyalojik öğretim. Pamukkale Üniversitesi Eğitim Fakültesi Dergisi, 55, 294-323.doi:10.9779.pauefd.1029432

\footnotetext{
*Doç. Dr., Pamukkale Üniversitesi, Eğitim Fakültesi, Matematik ve Fen Bilimleri Eğitimi Bölümü, Denizli. ORCID: 00000003-2897-6462, eucak@ pau.edu.tr

**Doç. Dr., Pamukkale Üniversitesi, Eğitim Fakültesi, Matematik ve Fen Bilimleri Eğitimi Bölümü, Denizli. ORCID: 0000-0001-6410-152X, asavran@pau.edu.tr

***Tezsis yüksek lisans öğrencisi, Pamukkale Üniversitesi, Eğitim Bilimleri Enstitüsü, Matematik ve Fen Bilimleri Eğitimi Anabilim Dal1, Denizli. ORCID:0000-0001-5302-8152, arifesevis@gmail.com

****Tezsis yüksek lisans öğrencisi, Pamukkale Üniversitesi, Eğitim Bilimleri Enstitüsü, Matematik ve Fen Bilimleri Eğitimi Anabilim Dalı, Denizli, ORCID: 0000-0001-6436-9227, sibelusta2824@ gmail.com
} 


\section{Giriş}

Öğrenme ortamında diyalog sadece belli bir konuda fikir alışverişi ve uzlaşma değil, aynı zamanda öğrencilerin kendi başlarına daha önceden edinemedikleri bilgileri kazanma süreci olarak görülür (Game ve Metcalfe, 2009). Diğer bir deyişle, diyalog sürecinde yaşanan yoğun sosyal etkileşim sayesinde bireyler kendilerini ve diğer katılımcıları eğitmektedirler. Dolayısıyla diyalog, pedagojik bir potansiyele sahiptir. Bu gücünü sosyal yapılandırmacı felsefenin de dayanağı olan sosyal etkileşimden almaktadır. Bu nedenle öğrenme ve öğretimin sosyo-kültürel bir yanının da olduğu düşüncesiyle araştırmacılar diyalojik öğretim kavramını kullanmışlardır (örn. Alexander, 2006; Nystrand, Gamoran, Kachur ve Prendergast, 1997). Alexander (2006) konuşma dilinin, öğrencilerin sınıf söylemine dahil olmaları vasıtasıyla düşünme süreçlerini etkileme yönünde bir firsat sunduğu için öğretimde merkezi bir rol oynadığını; diyalojik öğretimin de öğrencileri işin içine çekmek, düşünmelerini harekete geçirmek, genişletmek ve onların öğrenmesini ve anlamasını geliştirmek için konuşmanın bu gücünü kullandığını vurgular.

Diyalojik öğretimdeki en kritik düşünce, sınıf konuşmasında kendi bilgi dağarcıklarını oluşturmada katılımcılar olarak öğrencilere ne derece aktif roller verildiği ile ilgilidir (van Zee, Iwasyk, Kurose, Simpson ve Wild, 2001). Dolayısıyla diyalojik öğretimde öğretmenin rolü, öğrencilerin birlikte konuşması ve düşünmesi için etkileşimsel bir alan yaratmaktır. Böylece öğrenciler arasında etkileşim başlar (van der Veen, van Kruistum ve Michaels, 2015), bu da farklı görüş ve anlayışların keşfedilmesine destek olur (Nystrand, Wu, Gamoran, Zeiser ve Long, 2003). Diyalojik öğretimin diğer önemli özellikleri, öğrenci özerkliği ve sınıf içinde en azından belli bir düzeyde öğrencilerin olayların akışını etkilemelerine izin verilmesi gerçeğidir (Reznitskaya ve Gregory, 2013). Farklı seslerin duyulmasına izin verilecek biçimde öğrencileri zengin ve teşvik edici söylem içine katan diyalojik öğretimde sorgulama; düşünmeyi derinleştirir, zihinsel aktiviteyi ve üst düzey düşünme becerilerini geliştirir (Chin, 2006).

Sınıf söylemi ile bağlantılı olarak, bilim insanları, sınıf söyleminin ampirik incelemesi için tanımlamalar yapmışlardır. İçinde öğrencilerin bakış açıları da dahil çok çeşitli fikirlerin temsil edildiği sınıf söylemi diyalojik (Mortimer ve Scott, 2003; Nystrand, 1997) olarak tanımlanmıştır. Bunun aksine, içinde dikkatin belli bir bakış açısına odaklandığı ve hazır bilgilerin aktarıldığı sınıf söylemini Mortimer ve Scott (2003) otoriter; Nystrand (1997) ise monolojik olarak tanımlamıştır. Otoriter söylemin temel özelliği öğretmenin yanıtlarını zaten bildiği test sorularının hakim olmasıdır (Nystrand, 1997). 

Ayrıca, otoriter söylem tipik bir biçimde öğrencilerin katkılarının öğretmen tarafından açık bir biçimde değerlendirilmesini içerir (Scott, Mortimer ve Aguiar, 2006) ve genellikle bir öğretmen başlatması (initiation) —öğrenci yanıtı (response) - öğretmen değerlendirmesi (evaluation) olarak adlandırılan IRE örüntüsü vasıtasıyla sergilenir (Mortimer ve Scott, 2003). Bu şekilde, öğretmen bilginin birincil kaynağı olarak konumlandırılırken, sınıf söylemi üzerinde sıkı bir kontrol uygular. Bunun aksine, diyalojik söylemin temel özelliği, öğretmen tarafından hakiki soruların kullanılmasıdır (Scott vd., 2006). Başka bir ifadeyle bu tür soruların özelliği öğrencilerin düşüncelerini ortaya koymayı amaçlaması ve direkt öğretmen değerlendirmesinin olmayışıdır (Almahrouqi ve Scott, 2012; Scott ve Ametller, 2007; Scott vd., 2006). Bunun yerine, öğretmenler, öğrencilerin verdikleri yanıtları sonraki sorulara entegre ederek ya da öğrenciler tarafindan ortaya sürülmüş olan bakış açıları üzerine odaklanarak öğrencilerin yapmış oldukları katkıları kullanırlar. Bu şekilde, öğrenciler sınıf söylemine önemli katkı sağlayıcılar olarak konumlandırılırlar.

Diyalojik öğretim, öğrencilere daha fazla söz hakkı, anlam üretme ve daha adil öğrenme firsatları sağladığı için fen eğitiminde oldukça ilgi çekmektedir (Resnick, Asterhan, ve Clarke, 2015). Fen derslerinde diyalojik öğretim, yalnızca sınıfta katılımcılar arasında karşılıklı etkileşim olarak değil, aynı zamanda öğretmenin değişik fikirler arasındaki (örneğin günlük bilgiler ve bilimsel bilgiler) diyaloğu yönetmesi olarak da anlaşılabilir (Mortimer ve Scott, 2003). Ulu (2017), fen derslerinde “öğretim süreci tek bir görüşe odaklanan, içeriğin sınırlarının net bir şekilde çizildiği, öğretmenin konuşmayı yönlendirdiği ve öğrenci fikirlerinin görmezden gelindiği otoriter söylemden uzaklaştırılmalıdır” (s. 623) vurgusunu yapmış ve otoriter öğretimle mücadele etmek için sınıf uygulamalarında diyalojik öğretimin tercih edilmesi gerektiğini belirtmiştir.

\section{Fen Öğretimi Açısından Çalışmanın Önemi}

Diyalojik öğretimin yapılabilir ve yararlı olduğuna dair çalışmalar olmasına rağmen (Billings ve Fitzgerald, 2002; Kutnick ve Colwell, 2010; Mercer ve Littleton, 2007; Scott, Ametller, Mortimer ve Emberton, 2010); araştırmalar, fen içeriğinin ele alınması üzerine bir vurgu ile öğretmen tarafından tartışmaların yönlendirildiği otoriter sınıf söyleminin hakim olma eğiliminde olduğunu (Hofstein, Eilks ve Bybee, 2011; Kılınç, Demiral ve Kartal, 2017; Levinson, 2004; Levinson vd., 2001; Osborne, Duschl ve Fairbrother, 2002; Ratcliffe ve Millar, 2009; Tidemand Nielsen, 2017) bu yüzden de sınıf söyleminde öğrencilerin bakış açılarına çok az bir yer bıraktıklarına dikkat çekmektedir (Lyons, 2006; Osborne vd., 2002). Bunun nedeni Corden'e (2009) göre, muhtemelen öğretmenlerin öğrenciliklerinde bu türden 
E, Uçak, A, S. Gencer, A.Seviş ve S, Usta/ Pamukkale Üniversitesi Eğitim Fakültesi Dergisi, 55, 294-323, 2022297 bir öğretim biçimiyle karşılaşmamış ve hizmet öncesi eğitimlerinde de bunun üzerine bir eğitim almamış olmalarıdır.

Literatür incelendiğinde yukarıda bahsedilen çalışmaların öğretmen konuşmalarına odaklandığı görülmektedir. Ancak diyalojik ve otoriter sınıf ortamlarına dair öğrenci görüşlerinin alındığı hiçbir araştırmaya rastlanmamıştır. Oysaki öğrencilerin de diyalojik öğretime ilişkin görüşleri oldukça önemlidir. Bu bağlamda çalışmada, uygulama öncesindeki ders video analizleri incelendiğinde oldukça otoriter söylemlere sahip olduğu görülen bir fen bilgisi öğretmeninin aldığı eğitimden sonra sınıfında sosyobilimsel (SBK) bir konu olan genetiği değiştirilmiş organizmalar (GDO) konusunda gerçekleştirdiği diyolojik öğretim ortamına ilişkin olarak öğrenci görüşleri alınmış ve öğrencilerden daha önce işlenen fen dersleri ile GDO konusunda diyalojik öğretimin yapıldı̆̆ı derse ilişkin görsel modellemelerini resim çizerek açıklamaları istenmiştir. Çalışma kapsamında GDO konusunda diyalojik öğretimle Bilim Uygulamaları dersi bilim etiği teması-biyoteknoloji konusunda yer alan GDO ile ilgili amaçlara ulaşılmasında öğretmenlere rehberlik sağlayacaktır.

\section{Çalışmanın Amacı}

Bu çalışmada, fen öğretiminde sosyobilimsel bir konuda diyalojik öğretim gerçekleştirirken Mortimer ve Scott (2003) tarafından geliştirilen iletişimsel yaklaşımı baz alan ve dersini diyalojik söylemlere dayalı yapılandıran bir fen öğretmeninin dersinin öğrenci gözüyle analizine yer verilmiştir. Öğrenci katılımını ve bağımsızlığını geliştirmek, anlamlı öğrenmeyi sağlamak amacında olan bir öğretmenin yer aldığı bu araştırmada öğretmenöğrenci etkileşimleri ve öğrencilerin konumlandırılmaları bağlamında analiz edilmiştir. Özellikle, öğrencilerin diyalojik bir öğrenme ortamında öğretmen tarafından nasıl konumlandırıldı̆̆ 1 ve onların kendilerini sınıf uygulamasında katılımcılar olarak ve ele alınan konu ile bağlantılı olarak nasıl konumlandırdıkları incelenmiştir. $\mathrm{Bu}$ bağlamda araştırmada şu sorulara cevap aranmaktadır:

1. Sosyobilimsel bir konu olan GDO konusunda diyalojik öğretimle gerçekleşen derse ilişkin öğrenci görüşleri nelerdir?

2. Sosyobilimsel bir konu olan GDO konusunda diyalojik öğretimle gerçekleşen ders ile önceki fen derslerine ilişkin öğrencilerin zihinsel modellemeleri nasıldır? 


\section{Yöntem}

\section{Araştırma Deseni}

$\mathrm{Bu}$ çalışmada nitel araştırma deseni kullanılmıştır. Nitel araştırma "gözlem, görüşme ve doküman analizi gibi nitel veri toplama yöntemlerinin kullanıldığı, algıların ve olayların doğal ortamda gerçekçi ve bütüncül bir biçimde ortaya konmasına yönelik nitel bir sürecin izlendiği araştırma" (Yıldırım ve Şimşek, 2006, s. 39) olarak tanımlanabilir. Çalışmada diyalojik öğrenme ortamındaki öğrencilerden oluşan tek bir analiz birimi olduğu için bütüncül tek durum çalışması deseni kullanılmıştır. Araştırma Pamukkale Üniversitesi Sosyal ve Beşeri Bilimleri Bilimsel Araştırma ve Yayın Etiği Kurulunun 25/02/2021 tarihli 68282350/2018/G04 sayılı onayı ile etik ilkeler doğrultusunda yürütülmüştür.

\section{Çalışma Grubu}

Amaçlı bir şekilde seçilen çalışma grubunun fen bilgisi öğretmeni, 14 y1llık mesleki tecrübesi olan ve Pamukkale Üniversitesi tezsiz yüksek lisans programı kapsamında seçmeli bir ders olan Fen Öğretiminde Diyalojik Öğretim ve İletişimsel Yaklaşım dersini almıştır. Birinci yazar tarafından bir akademik dönem boyunca haftada üç ders saati olarak yürütülen dersin ana hedefi, ortaokul fen bilimleri dersi programına uygun ders kazanımlarına yönelik fen derslerinde diyalojik öğretimin kullanılmasını içermektedir. Derslerin bitiminden sonra, çalışma grubunun öğretmeni sosyobilimsel bir konu olan GDO konusunda diyalojik öğretime dayalı bir ders tasarısı oluşturmayı ve dersini o şekilde yürütmeyi istemiştir. Öğretmenin gönüllü olarak dersi seçmiş olması ve araştırma başlamadan önce sosyobilimsel konularda ve sosyobilimsel olmayan diğer fen konularında işlemiş olduğu derslerinde oldukça otoriter olduğu görüldüğü için bu araştırmaya katılmaya davet edilmiştir. Araştırmanın etik ilkeleri doğrultusunda öğretmenin ismi gizli tutulmuş ve çalışmada A öğretmeni olarak kodlanmıştır.

$\mathrm{Bu}$ araştırmanın gerçekleştirildiği ortam, 2020-2021 eğitim-öğretim yılında Denizli ilinde yer alan sosyo-ekonomik düzeyi alt seviyede olan bir devlet ortaokuludur. Çalışma grubu 13-14 yaşlarındaki 8. sınıf 20 öğrenciden oluşmaktadır. Uygulama sonrasında öğretmenin sınıfından derslerine sürekli, ara ara ve hiç katılmayı tercih etmeyen ikişer öğrenci olmak üzere toplam altı öğrenci ile işlenen ders ile ilgili yarı yapılandırılmış görüşmeler yapılmıştır ve yine aynı öğrencilerin çizimleri çalışmaya dahil edilmiştir. Çalışmanın etik kuralları açısından öğrenciler A1, A2, A3, A4, A5 ve A6 olarak kodlanmıştır. Covid-19 nedeniyle uygulama dersleri online olarak gerçekleşmiştir. 
E, Uçak, A, S. Gencer, A.Seviş ve S, Usta/ Pamukkale Üniversitesi Eğitim Fakültesi Dergisi, 55, 294-323, 2022299 Öğrenciler, etik ilkelere uygun bir biçimde çalışmaya katılmaya davet edilmiştir. Öğrencilerin ailelerine veli onam formu gönderilerek çocuğunun çalışmaya katılmasına izin verip/vermediğini imzalı olarak beyan etmesi istenmiştir. Bu bağlamda öğrenciler ve aileler, araştırmanın genel amacı ve çalışmaya katılmanın gönüllülük esasına dayandığı konusunda bilgilendirilmiştir. İsimlerinin gizli tutulacağına dair bilgi verilmiş ve çalışmadan istedikleri zaman çıkabilecekleri söylenmiştir.

\section{Veri Toplama Araçları}

$\mathrm{Bu}$ çalışmada farklı veri toplama kaynakları kullanılmış olup, bunlar; öğretmenin sınıf içi uygulamalarına ait video kamera kayıtları, öğrencilerle yapılan görüşmeler ve öğrencilerin yapmış olduğu çizimlerdir.

\section{Sınıf içi uygulamalarına ait videolar}

Araştırmada, çalışma öncesi ve çalışma kapsamında A öğretmenin derslerinin iletişimsel yaklaşım açısından görülmesi, öğretmen-öğrenci etkileşimi, öğretmen-öğrenci rolü, yani öğretmen ve öğrencilerin sınıf içi konumlandırılmasının görülebilmesi açısından öğretmenin derslerine ait video kamera kayıtları kullanılmıştır.

\section{Görüşme formu}

Çalışmada veri toplama yöntemi olarak yarı yapılandırılmış görüşme tekniği kullanılmıştır. Bu teknik, özel bir konuda derinlemesine soru sorma ve cevap eksik veya açık değilse tekrar soru sorarak, durumu daha açıklayıcı hale getirip cevapları tamamlama firsatı vermesi açısından avantajlıdır (Çepni, 2007). Araştırmacılardan birinin katılımcılarla gerçekleştirdiği görüşmelerin ses kaydı katılımcıların onayı alınarak kaydedilmiştir. Görüşmelerden sonra ses kayıtları, yazılı metin haline dönüştürülmüştür. Görüşmeler, araştırmacılar tarafindan hazırlanan görüşme formuna bağlı kalınarak gerçekleştirilmiştir. Görüşme formunun geliştirilmesi için öncelikle belirlenen amacı en iyi yansıtabilecek sorular oluşturulmuştur. Araştırmanın amacına uygun olarak açık ve anlaşılır sorular yazılmıştır. Araştırmada hazırlanan yarı-yapılandırılmış görüşme formu için uzman görüşü alınmıştır. Hazırlanan sorular bu konuda çalışmaları olan iki akademisyene iletilerek incelemeleri istenmiş ve gerekli dönütler alınarak son şekli verilmiştir. Ayrıca sorular araştırma kapsamında olmayan başka bir öğrenciye yönlendirilmiş ve soruların anlaşılabilirliği test edilmiştir. Anlamsız ve gereksiz görülen sorular formdan atılarak görüşme formuna son sekli verilmiştir. Yarı yapılandırılmış görüşme formunda toplam 16 soru bulunmaktadır. 


\section{Ö ̆̆rencilerin yapmış olduğu çizimler}

Öğrencilerden sosyobilimsel bir konu olan GDO konusunda diyalojik olarak işlenilen ders ile diğer fen derslerini resim çizerek karşılaştırmaları ve çizdikleri resimlerin altına öğretmen ve öğrencilerin resimde ne yaptığını yazmaları istenmiştir.

\section{Verilerin Toplanması}

Verilerin toplanması aşaması aşağıda özetlenmiştir:

* Çalışmaya gönüllü olarak katılan A öğretmeni, Covid-19 sürecinde çevirim-içi işlediği ve kayıt altına almış olduğu 4 haftalık ders videolarını eğitimler öncesi araştırmacılara sunmuştur. Araştırmacılardan ikisi tarafından derslerine ait videolar izlenmiş ve Mortimer ve Scott (2003) tarafından geliştirilen iletişimsel yaklaşım açısından değerlendirilmiştir.

* Dersin büyük bir bölümünü otoriter etkileşimsiz ve otoriter etkileşimli sürdürdüğü tespit edilen öğretmene 12 hafta boyunca yapılandırmacı öğrenme kuramı ve 5E modeli, sosyal yapılandırmacılık, diyalojik öğretim, iletişimsel yaklaşım, söylem ve söylem desenleri, sınıfta etkili soru sorma stratejileri, sınıf içi normlar, bekleme süreleri, diyalojik olarak tasarlanan ve fen derslerinde anlamlı öğrenmeyi baz alan ders tasarılarını inceleme (Mortimer ve Scott, 2003) tarafından geliştirilen paslanmaya ilişkin ders tasarısı), argümantasyon, kavram karikatürleri, sokratik tartışma gibi sınıf içi konuşmayı destekleyici tekniklerin verilmesi, literatürde yapılan makalelerin okunması ve yorumlanması, diyalojik öğretime dayalı ders videolarının izlenmesi ve ders videolarındaki öğretmen-öğrenci, öğrenci-öğrenci konuşmalarını mikro düzeyde analizlerini yapmaya yönelik eğitimler verilmiştir.

* Eğitimler bittikten sonra öğretmen 8. sınıflarda Bilim Uygulamaları dersi kapsamında bilim etiği teması altında yer alan toplamda programda altı ders saati olarak önerilen GDO konusunu içeren biyoteknoloji etkinliğine göre dersini tasarlamıştır. Kazanımlarda bulunan GDO’yu açıklama, GDO’lu ürünlerin nasıl elde edildiğini araştırma, GDO tarımının yapılmasının ekolojik dengeye ve ülke ekonomisine etkisini değerlendirme, GDO’lu ürünleri küresel açlık sorunları açısından değerlendirme, GDO’lu ürünleri tüketip tüketmeme konusunda karar verme ve GDO'lu ürünleri etik konular açısından tartışmaya dayalı olarak dersini diyalojik öğretimle Mortimer ve Scott'un (2003) fen derslerinde anlamlı öğrenmeye yönelik ortaya koyduğu iletişimsel yaklaşımı baz alarak yürütmüştür. 
E, Uçak, A, S. Gencer, A.Seviş ve S, Usta/ Pamukkale Üniversitesi Eğitim Fakültesi Dergisi, 55, 294-323, 2022301

* Ders bitiminde öğretmenin sınıfından derslerine sürekli, ara ara ve hiç katılmayı tercih etmeyen ikişer öğrenci olmak üzere toplam altı öğrenci ile işlenen ders ile ilgili yarı yapılandırılmış görüşmeler gerçekleştirilmiştir. Ayrıca öğrencilerden ders bitiminde diyalojik bir şekilde işlenen ders ile daha önce işledikleri fen derslerini işleyiş biçimini açısından resim çizerek karşılaştırmaları ve çizdikleri resimlerin altına çizimlerinde ne anlatmak istediklerini yazmaları (illüstrasyon) istenmiştir.

\section{Verilerin Analizi}

Araştırma kapsamında elde edilen görüşme verilerinin analizinde nitel veri analizi tekniklerinden içerik analizi kullanılmıştır. İçerik analizinde veriler derinlemesine analiz edilir ve bu yolla önceden belirgin olmayan tema ve kodlar oluşturulur. İçerik analizinde temelde yapılan işlem, birbirine benzeyen verileri belirli kavramlar ve temalar çerçevesinde bir araya getirmek ve bunları okuyucunun anlayabileceği bir biçimde düzenleyerek yorumlamaktır. Bu amaçla içerik analizi yapılırken tümevarımcı yaklaşım izlenir (Yıldırım ve Şimşek, 2006). Araştırmanın güvenirliği, Miles ve Huberman'ın (1994) formülü [Güvenirlik = görüş birliği/ (görüş birliği + görüş ayrılığı) $]$ kullanılarak hesaplanmıştır. Kod güvenirliği \%89 olarak hesaplanmıştır. Resimler ise yorumlanarak sunulmuştur.

\section{Bulgular}

\section{Öğrencilerle Yapılan Görüşmelerden Elde Edilen Bulgular}

Öğrencilerle gerçekleştirilen yarı yapılandırılmış görüşmelerden sonra veriler içerik analizi yoluyla analiz edilmiş ve verilerden elde edilen bulgular Tablo 1.'de sunulmuştur.

Tablo 1. Yarı Yapılandırılmış Görüşmelerden Elde Edilen Temalar ve Kodlar

\begin{tabular}{lll}
\hline Temalar & Kodlar & Değinen Öğrenciler \\
\hline SBK' da diyalojik & Öğretmenin dersteki rolü & \\
öğretimde öğretmen- & Ayna (Bilgiyi yansıtan) & - \\
öğrenci rolü & $\begin{array}{l}\text { Kutup yıldızı (Yol gösteren) } \\
\text { Öğgrencinin dersteki rolü }\end{array}$ & A1, A2, A3, A4, A5, A6 \\
& Araştıran derse aktif katılan & A1, A3, A4, A5, A6 \\
& Fikirlerini özgürce söyleyip savunan & A1, A2, A3, A4, A5, A6 \\
SBK' da diyalojik & Zamanlama & \\
öğretimde sınıf & Soruları cevaplamada yeterli düşünme & A1, A2, A3, A4, A5, A6 \\
normları & zamanı & \\
& Sorular hakkında yeterli konuşma süresi & A1, A2, A3, A4, A5, A6
\end{tabular}


Söz alma

Öğretmenin eşit söz hakkı vermesi

Düşünce ve fikirlere saygı duyulması

Demokratik, adil ve özgür sınıf ortamı

SBK' da diyalojik öğretimde öğrenme ortam 1

\section{Beğenilen öğrenme ortamı}

Farklı fikirlerin paylaşılıp tartışıldığg bir

ortam

$$
\mathrm{A} 1, \mathrm{~A} 2, \mathrm{~A} 3, \mathrm{~A} 4, \mathrm{~A} 5, \mathrm{~A} 6
$$

Fikirlere müdahale edilmemesi

$\mathrm{A} 1, \mathrm{~A} 3, \mathrm{~A} 4, \mathrm{~A} 5$

Fikirlerin birbiriyle bağlanarak öğrenilmesi

$\mathrm{A} 3, \mathrm{~A} 4, \mathrm{~A} 5, \mathrm{~A} 6$

Tek bir cevabın olmaması

A4, A5, A6

Dersi eğlenceli ve ilgi çekici hale getirmesi

$\mathrm{A} 1, \mathrm{~A} 2, \mathrm{~A} 3, \mathrm{~A} 4, \mathrm{~A} 5$

\section{Beğenilmeyen öğrenme ortamı}

Hep bir ağızdan konuşulması

A1, A6

Fikirlere müdahale edilmesi

A2, A6

Ders süresinin yetersiz olması

A5

\section{Öğrenme ortamında değişiklik yapma}

Farklı sınıflarla kalabalık ortamda ders

işlemek

Dersi materyallerle destekleme

SBK' da diyalojik

Dersin öğrencide uyandırdığı duygular

öğretimde öğrenci

Olumlu Duygular (Merak, ilgi, hoşlanma,

$\mathrm{A} 1, \mathrm{~A} 2, \mathrm{~A} 3, \mathrm{~A} 4, \mathrm{~A} 5, \mathrm{~A} 6$

özellikleri istek)

Hem olumlu hem olumsuz duygular

A3, A4

SBK' da diyalojik Öğrencilerin birbirlerinin fikirlerine

öğretimde öğrenci-

etkisi

öğrenci etkileşimi

Fikirlerin farklılaşmaması

A1, A2, A3

Fikirlerin farklılaşması

\section{SBK’ da diyalojik öğretimde öğretmen-öğrenci rolü}

Katılımcı öğrencilerin, SBK'da diyalojik öğretimde, öğretmenin ve öğrencinin dersteki rolüne ilişkin ortaya çıkan temalar ait görüşlerine aşağıda sunulmuştur.

Öğretmenin dersteki rolüne ilişkin görüşler. Diyalojik öğretimle işlenen derslerin bitiminde öğrencilere “Öğretmeninizin son işlenen derslerde rolünü aynaya mı yoksa kutup yıldızına mı benzetirsiniz? sorusu soruldu. Görüşmeye katılan tüm öğrenciler 
E, Uçak, A, S. Gencer, A.Seviş ve S, Usta/ Pamukkale Üniversitesi Eğitim Fakültesi Dergisi, 55, 294-323, 2022303 öğretmenlerinin son derslerdeki rolünü kutup yıldızına benzettiklerini dile getirmişlerdir. $\mathrm{Bu}$ öğrencilerden A4 görüşlerini şu şekilde belirtmiştir:

Bu dersi işlerken öğretmenimizin rolünü bize yol gösterene benzettim. Çünkü herkes GDO ile ilgili fikrini açıçca ifade ettiği için bize yol gösterdi. Düşüncelerimize ortak oldu. Ama normal bir fen dersi olsaydı bilgilerini yansıtana benzetirdim. Çünkü diğer fen derslerinde öğretmenim hep konuyu anlatıyor sadece soruları cevaplamamıza yardımcı oluyor. Bilgileri bize yansıtıyor o zaman diye düşündüm (Görüşme Kaydı: A4).

Biz araştırdığımız konuları farklı fikirler öne sürerek tartışmıştık o yüzden yol gösteren yani söz hakkı verendi. O yüzden kutup yıldızına benzettim diyen A5 ise görüşlerini şu şekilde belirtmiştir:

Ben kutup yıldızına benzetirdim. Çünkü yol gösteren, herkes araştırma yaptığı için herkes farklı bilgiler öne sürüyordu ve bu farklı fikirlerde arkadaşımın araştırdığı benim araştırmadığım konularda vardı bu yüzdende farklı bilgileri de öğrendim. O yüzden de bilgileri yansitan değil de yol gösterendi bence. Biz araştırdığımız konuları farklı fikirler öne sürerek tartışmıştık o yüzden yol gösteren kutup yıldızına benzettim (Görüşme Kaydı: A5).

Ders işlerken ve tartışırken kendi düşüncelerini söylemedi ve bize yol gösterdi diyen A1 de görüşlerini şu şekilde belirtmiştir: "Ben bu derste öğretmenimizi kutup yıldızına benzettim. Çünkü dersi anlatırken ve tartışırken kendi düşüncelerini söylemedi ve bize söz hakk1 vererek yol gösterdi” (Görüşme Kaydı: A1).

Öğrencinin dersteki rolüne ilişkin görüşler. Öğrencilerden A2 öğrencisi hariç diğer öğrenciler (A1, A3, A4, A5, A6) konuyla ilgili araştırmalar yapıp derse aktif katıldıklarını belirtmişlerdir. Ayrıca tüm öğrenciler fikirlerini özgürce söyleyip, görüşlerini savunduklarını belirtmişlerdir. Kendi fikirlerimi savundum ve derse katıldım diyen A1 öğrencisi görüşlerini şu şekilde belirtmiştir: "Aktiftim ve ilgiliydim çünkü kendi fikirlerimi savundum ve derse katıldım. Derse katılmamda beni daha da ilgimi çekti. Dersi hem seviyorum hem de ilgi duyduğum için fikirlerimi savunarak da aktifliğimi sergiledim" (Görüşme Kaydı: A1).

Öğrencilerin fikirlerini özgürce söyleyip, kendi fikirlerini savunduğuna dikkat çeken A4 öğrencisi görüşlerini şu şekilde belirtmiştir: "Bu dersle ilgili yaptığımız tartışmalar, konuşmalar hoşuma gitti çünkü herkes kendi fikirlerini açıkça ifade edebildi, fikirlerinin 

arkasında durdular. Fikirlerini savunabildiler. Benim GDO ile yapılan tartışmalar ve konuşmalar hoşuma gitti” (Görüşme Kaydı: A4).

Ders içindeki sorumluluklarımız arttı diyen A2 öğrencisi görüşlerini şu şekilde belirtmiştir:

Farklı olduğunu düşünüyorum çünkü normal bir dersi öğretmenimiz dersi yönetirken soruları okuyup söz hakkı verirken vs. yani dersi öğretmen yönetiyordu. Bu derste daha çok biz konuştuk biz söz hakkı aldık. Öğretmenimiz sadece sırasıyla sorular sorup fikirlerimizi aldı. Tartışma ortamında genelde biz konuştuk. Öğretmenimiz kendi fikrini söylemedi. Bu şekilde olunca daha çok sorumluluk alıyoruz. Normal derste çok az konuşurken bu derste zaten çok konuşuyoruz artı dersteki tartışma ortamını yönetmemiz gerekiyor. Böylece daha fazla sorumluluk alıyoruz (Görüşme Kayd1: A2).

\section{SBK' da diyalojik öğretimde sınıf normları}

Katılımcı öğrenciler SBK da diyalojik öğretimde zamanlama ve söz alma açısından sınıf normlarına ilişkin görüşlerini dile getirmişlerdir.

Zamanlama açısından görüşler: Öğrenciler (A1, A2, A3, A4, A5, A6) zamanlama açısından soruyu cevaplamada yeterli düşünme zamanı ve soru hakkında yeterli konuşma zamanına sahip olduklarını dile getirmişlerdir ve bazı öğrenciler görüşlerini şu şekilde ifade etmiştir: "Evet verdi. Zaten herkes öğretmenimiz yeterli süre vermeden önce düşünüp öyle söylüyorlardı ve yeterli süre verilmiş oldu” (Görüşme Kaydı: A1). "Evet öğretmenim soru sorduktan sonra fikirlerimizi söylememiz için yeterli süre verdi. Hatta bir konu üzerinde bayağı düşündük, mantık yürüttük. Fikirlerimizi söylememiz için baya süre verdi” (Görüşme Kaydı: A4). "Yeterli süre verildi ben zaten çok böyle zamandan çalmayıp kısa bir şekilde cevabımı açıklayıcı veririm. Yani ben zamanın yeterli olduğunu düşünüyorum. Gayet iyiydi ve verilen süre yeterliydi” (Görüşme Kaydı: A2).

Söz alma açısından görüşler. SBK' da diyalojik öğretimle işlenen bu derste söz alma açısından öğrenciler (A1, A2, A3, A4, A5, A6) öğretmenin herkese eşit söz hakk1 verdiğini dile getirmiştir ve bazı öğrencilerin görüşleri şu şekilde belirtmiştir:

Öğretmenimiz bize istediğimiz zaman söz hakkı verdi. İstediğimiz zaman konuşabildik. Sırayla konuştuk birimiz bir defa diğeri on defa konuşmadı. Sırayla konuştuk herkes birbirinin fikrine saygı duydu. Adaletli bir şekilde dersimizi işledik. Güzeldi yani eğlenceli geçti (Görüşme Kaydı: A4). 
E, Uçak, A, S. Gencer, A.Seviş ve S, Usta/ Pamukkale Üniversitesi Eğitim Fakültesi Dergisi, 55, 294-323, 2022305

Şöyle sırasıyla zaten söz hakkı verildi. Bence bu daha güzel. Çünkü diğer konuşmayanların işine gelirdi bu. Biz konuşurduk onlar derste dururlardı. Ara sıra belki konuşurlardı. Yani sırasıyla söz hakkı verildi. Böyle olması da benim için gayet iyiydi, böyle olmasını isterdim böyle de oldu zaten (Görüşme Kaydı: A2).

Öğrencilerden (A1, A2, A3, A4, A5, A6) düşünce ve fikirlere sayg1 duyulduğunu dile getiren bazı öğrencilerin görüşleri şu şekildedir:

Arkadaşlarımın benim fikrime saygı duyduğunu düşünüyorum çünkü ben konuşurken hiç kimse sözümü kesmedi. Ben de konuşurken arkadaşlarımın sözünü kesmedim. Birbirimize saygı duyduk. Benim fikirlerime saygı duydukları için ben çok mutlu oldum. Çok sevindim ama fikirlerime saygı duyulmasaydı çok üzülürdüm. Yani konuşmamı bölselerdi, konuşmama izin vermeselerdi çok üzülürdüm. Ama fikirlerime saygı duydular (Görüşme Kaydı: A3).

Tartışma sırasında arkadaşlarımın benim fikrime saygı duyduğunu düşünüyorum. Çünkü arkadaşlarım hem anlayışı hem de sana katılıyorum, katılmıyorum diyerek benim fikrime saygı duyarak bunları söylediler. Hem kendi fikirleriyle de karşılaştırmış olmalılar ki bazıları bana katıldığını, bazıları da katılmadıklarını söyledi. Bana saygı duymasalardı beni umursamaz kendi fikir ve düşünceleriyle hareket ederlerdi hiç benim fikrimi sorgulamadan (Görüşme Kaydı: A5).

Bazı öğrencilerin (A1, A3, A4) demokratik, adil ve özgür bir sınıf ortamında ders işlendiğine dair görüşlerini belirtmiş olup, bunlardan A3 görüşünü şu şekilde belirtmiştir: "Evet istediğim zaman konuşabildim. Arkadaşlarımın sözünü kesmeden adaletli bir şekilde herkes eşit bir şekilde konuşabildi. Zaten sınıftaki herkes konuştu istediği zaman öğretmenimiz söz hakkı verdiğinde. Adaletli bir şekilde kimsenin sözünü kesmedik” (Görüşme Kayd1: A3).

\section{SBK' da diyalojik öğretimde öğrenme ortamı}

Katılımcı öğrenciler SBK da diyalojik öğretimde öğrenme ortamına ilişkin olarak beğendikleri, beğenmedikleri ve ortamda değiştirmek istedikleri özellikleri dile getirmişlerdir.

Beğenilen öğrenme ortamına ilişkin görüşler. SBK da diyalojik öğretimle işlenen derste öğrencilerin dile getirdiği beğenilen öğrenme ortamı; farklı fikirlerin paylaşılıp, tartışıldığı bir ortam olması (A1, A2, A3, A4, A5, A6), fikirlere müdahale edilmemesi (A1, A3, A4, A5), fikirlerin birbiriyle bağlanarak öğrenilmesi (A3, A4, A5, A6), SBK tek bir 

cevabının olmaması (A4, A5, A6), SBK tartışılmasının dersi eğlenceli ve ilgi çekici hale getirmesi (A1, A2, A3, A4, A5) yönündedir.

Farklı fikirlerin paylaşılıp, tartışıldığı bir ortam olmasına dikkat çeken öğrencilerden A3 görüşlerini şu şekilde dile getirmiştir: "Benim dersle ilgili yaptığımız tartışmalar çok hoşuma gitti. Yaptığımız konuşmalar, arkadaşlarımızla bir konu üzerinde durduğumuz sorular, onlar üzerinde yaptığımız birbirimizle tartışıyoruz ya onun üzerinde onlar çok hoşuma gitti. Herkes kendi fikrini açıkça ifade edebildi onlar benim çok hoşuma gitti” (Görüşme Kaydı: A3).

Fikirlere müdahale edilmemesine dikkat çeken öğrencilerden A4 görüşlerini şu şekilde dile getirmiştir: “Öğretmenimiz ve arkadaşlarımız sözümü kesmediler. Birbirimizin sözünü kesmeden ders işledik. Birbirimizi kırmadan incitmeden dersimize devam ettik. Yani kesmediler sözümüzü” (Görüşme Kaydı: A4).

Fikirlerin birbiriyle bağlanarak öğrenilmesine dikkat çeken öğrencilerden A6 görüşlerini şu şekilde dile getirmiştir: "Ben araştırmıştım ama arada görmediğim bilgiler falan olabilir. Arkadaşlarımın görmediği bilgilerde olabilir. Benim gördüğümü arkadaşım görmez, arkadaşımın gördüğünü ben görmem böylece bilgiler tamamlanır birbiriyle. Birimizin söylediğine diğeri bir şey ekleyerek devam edilmesi güzeldi” (Görüşme Kaydı: A6).

SBK da tek bir cevabının olmamasına ve herkesin kendi fikirlerini savunduğuna dikkat çeken öğrencilerden A4 görüşlerini şu şekilde dile getirmiştir:

Ben bu GDO’ lu dersimizin diğer fen derslerimizden farklı olduğunu düşünüyorum. Çünkü bu derste herkes konuştu. Herkes kendi fikirlerini ortaya koydu. Herkes kendi fikirlerinin arkasında durdu. GDO’ nun tam bir cevabı olmadı̆̆ı için herkes kendi fikirlerini öne sürdü. Ama normal bir fen dersinde bir soru üzerinde tek bir doğru cevap olurdu. Herkes tek bir cevabı söylüyordu. Tek bir cevabı olurdu yani ben bu dersin diğer derslerimizden farklı olduğunu düşünüyorum bu açılardan da (Görüşme Kaydi: A4).

Dersi eğlenceli ve ilgi çekici hale getirmesine dikkat çeken öğrencilerden A1 ve A4 görüşlerini şu şekilde dile getirmiştir: "Evet farklı olduğunu düşünüyorum çünkü normal fen derslerinde ünite veya normal derslerimizi işliyoruz ama GDO'lu olan bu derste ortak bir yönümüz oldu. Herkes ortak bir konuya yöneldi ve daha bir eğlenceli geçti dersimiz. Herkes kendi fikirlerini savundu" (Görüşme Kaydı: A1). "Benim için ders iyi geçti güzel geçti 
E, Uçak, A, S. Gencer, A.Seviş ve S, Usta/ Pamukkale Üniversitesi Eğitim Fakültesi Dergisi, 55, 294-323, 2022307 dersimiz daha heyecanlı istekli geçti. Bunun nedeni dersi bu şekilde işlememiz" (Görüşme Kayd1: A4).

Beğenilmeyen öğrenme ortamına ilişkin görüşler. SBK' da diyalojik öğretimle işlenen derste öğrencilerin dile getirdiği beğenilmeyen öğrenme ortamı; hep bir ağıdan konuşulması, konuşmaların zaman zaman anlaşılamaması (A1, A6), fikirlere müdahale edilmesi (A2, A6), ders süresinin yetersiz olması (A5) yönündedir.

Hep bir ağızdan konuşulması bu yüzden de zaman zaman konuşmaların anlaşılamamasına dikkat çeken öğrencilerden A1 ve A6 görüşlerini şu şekilde dile getirmiştir: "Hepimiz tartışırken hep bir ağızdan konuşmuştuk ve bazı kişilerin söylediği cevaplar olmadı yani anlaşılmadı bu yüzden bu hoşuma gitmedi” (Görüşme Kaydı: A1). "Mesela bazen herkes söz hakkı istiyordu bir kişi konuşurken diğeri ben bir şey diyebilir miyim diye sözünü kesiyordu bu hoşuma gitmedi” (Görüşme Kaydı: A6).

Fikirlere müdahale edilmesine dikkat çeken öğrencilerden A2 görüşlerini şu şekilde dile getirmiştir: "Bir de sözümüzü kesenler de oldu. Fikrimizi söylerken müdahale edenler oldu, onun dişında gayet eğlenceli bir dersti” (Görüşme Kaydı: A2).

Ders süresinin yetersiz olmasına dikkat çeken öğrencilerden A5 görüşlerini şu şekilde dile getirmiştir: “Açıkçası benim pek beğenmedim bir özellik yoktu. Güzel geçti. Neleri beğenmedim... Sadece biraz kısa sürdü 6 dersten daha çok daha uzun sürseydi daha iyi olurdu (Görüşme Kaydı: A5).

Öğrenme ortamında değişiklik yapmaya ilişskin görüşler. SBK' da diyalojik öğretimle işlenen bu derste öğrenme ortamında değişiklik yapmak isteseniz ne yapardınız sorusuna ilişkin öğrencilerden A2 farklı sınıflarla kalabalık ortamda ders işlemek, öğrencilerden A1 ise dersi materyallerle destekleme yönünde görüş belirtmiştir.

Farklı sinıflarla kalabalık ortamda ders işlemeye dikkat çeken öğrencilerden A2 görüşlerini şu şekilde dile getirmiştir:

Tek sınıfla değil de iki sınıfla birlikte yapılsaydı daha güzel olurdu belki, daha kalabalık bir ortam. Çünkü birbirimizi tanıyoruz ve iyi kötü cevapları ne bileyim sınıftan biri şunu söyler diyebiliyoruz ama başka bir sınıftan kimseyi tanımadığımız için doğru düzgün daha böyle değişik olur daha güzel olabilir (Görüşme Kaydı: A2).

Dersi materyallerle desteklemeye dikkat çeken öğrencilerden A1 ise görüşlerini şu şekilde dile getirmiştir: "Bir değişiklik yapmak istesem ek olarak GDO ile ilgili maket 

yapılmasını isterdim. Yani bir domates maketi içine biber koyulup, yani biberin içi koyulup yapılabilir. Yani iki meyveyi birleştirebilen bir maket yapmayı isterdim" (Görüşme Kaydı: A1).

\section{SBK' da diyalojik öğretimde öğrenci özellikleri}

SBK da diyalojik öğretimle işlenen derste görüşmeye katılan tüm öğrenciler (A1, A2, A3, A4, A5, A6) olumlu duygulara sahip olduklarını, bazı öğrenciler (A3, A4) ise arkadaşları fikirlerine katılmadıklarında üzüldüklerini dile getirmişlerdir.

Aktif, istekli, meraklı ve heyecanlı olduğuna dikkat çeken öğrencilerden A5 görüşlerini şu şekilde dile getirmiştir: "Kendimi heyecanlı hissetmiştim ilk başlarda. İlk defa böyle bir derse katılmıştım acaba ne olacak diye sonrasında rahatlamaya başladım. Sonra, meraklı ve istekli oldum aktif oldum, etkin olduğumu düşünüyorum. Mutluydum derste yani” (Görüşme Kaydı: A5).

Arkadaşları kendisinin fikrine katılmadığında üzüldügünü dile getiren öğrencilerden (A3, A4) A4 görüşlerini şu şekilde dile getirmiştir:

Arkadaşlarımın benim fikrime katılmaları beni mutlu etti. Çok sevindim. Ama bazen de bu GDO' lu konu çok açık bir konu olduğu için bazı arkadaşlarım benim fikrime katılmadılar bu beni üzdü. Yanlış düşünüyormuşum gibi geldi. Kendimi savunma isteği geldi. Kendimi savundum (Görüşme Kaydı: A4).

\section{SBK’da diyalojik öğretimde öğrenci-öğrenci etkileşimi}

Öğrencilerin diyalojik öğretimle işlenen derslerdeki öğrenci-öğrenci etkileşimine yönelik görüşleri aşağıda sunulmuştur.

Fikirlerin farklılaşmamasına ilişkin görüşler. Fikrimin doğru olduğunu düşünüyorum, fikrimin arkasında durdum diyerek fikirlerinin farklılaşmadığına dikkat çeken öğrencilerden A2 görüşlerini şu şekilde dile getirmiştir:

Yani diğer arkadaşlarımın fikirlerini duyunca fikrimde bir değişiklik olmadı. Çünkü kendi fikirlerimin doğru olduğunu düşünüyordum. Sonradan işte tartışma ortamında bir değişiklik oldu mu? Bazı yerlerde sadece değişiklik yaptık ama komple fikrimi değiştirmedim fikrimin arkasında durdum. Yani onlar bir konuda zararlı diyorsa ben yararlı diyordum yani o şekilde. Yani bence fikrimizi değiştirmemeliyiz. Çünkü tabi ki doğruysa onların söyledikleri değiştirebiliriz ama ben fikrimin arkasında durdum. Çünkü fikrimin doğru olduğunu düşünüyordum (Görüşme Kaydı: A2). 
E, Uçak, A, S. Gencer, A.Seviş ve S, Usta/ Pamukkale Üniversitesi Eğitim Fakültesi Dergisi, 55, 294-323, 2022309

Bazı fikirlerin farklılaşmasına ilişkin görüş̧ler. Arkadaşlarımın fikirlerini duyunca benim de bazı fikirlerimde değişimler oldu diyerek bazı fikirlerinin farklılaştığına dikkat çeken öğrencilerden A5görüşlerini şu şekilde dile getirmiştir:

Diğer arkadaşlarımın fikirlerini duyunca bazı fikirlerimde değişiklik oldu. Çünkü onlar söylediğinde bende şöyle bir gözden geçirdim. O arkadaşım neden böyle demiş olmalı ki diye düşündüm. Bana kendi fikrim yanlış geldiğinde ona katıldım bazen, bazen de onun fikrinin yanlış olduğunu görünce kendi fikrimi savundum (Görüşme Kayd1: A5).

\section{Öğrencilerin Çizimlerine İlişkin Bulgular}

Aşağıda çalışmaya katılan öğrencilerin çizmiş oldukları resimler ve çizimlere dayalı olarak yapmış oldukları açıklamalar yer almaktadır.

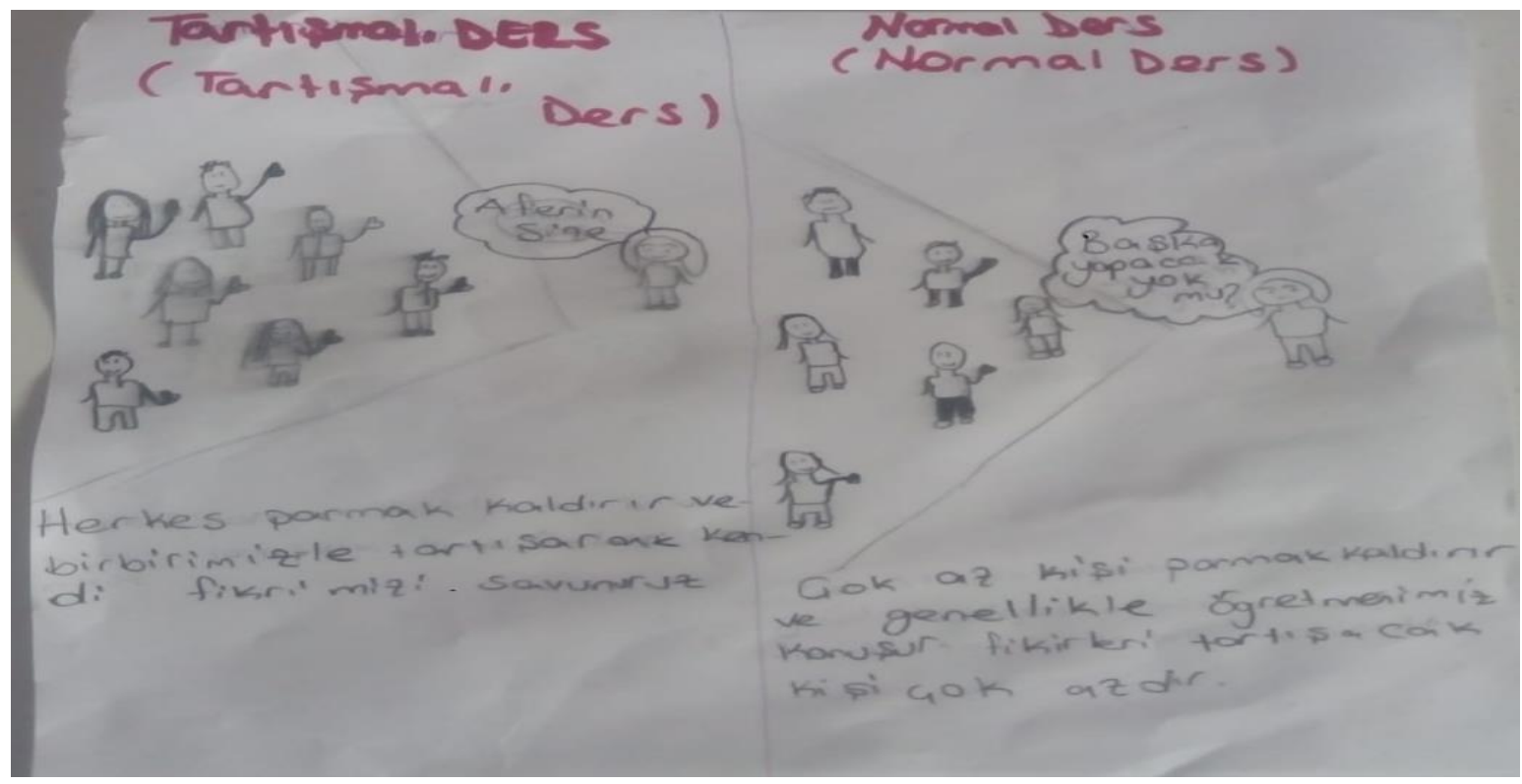

Şekil 1. Al'in diyalojik öğretimle işlenen ders ile daha önceki dersleri karşılaştıran resmi

Şekil 1'de verilen A1 çiziminde önceki derslere (sağda) normal ders diyerek "Çok az kişi parmak kaldırır ve genellikle öğretmenimiz konuşur. Konuşan kişi çok azdır.” yorumunu yapmıştır. GDO konusuna ilişkin diyalojik öğretimle işlenen derse (solda) ilişkin resimde ise tüm öğrenciler parmak kaldırmaktadır. Öğrencilerin derste aktif katılımlarına dikkat çekmiş ve açıklamasını, "Herkes parmak kaldırır ve birbirlerimizle tartışarak kendi fikirlerimizi savunuruz.” şeklinde yapmıştır. 


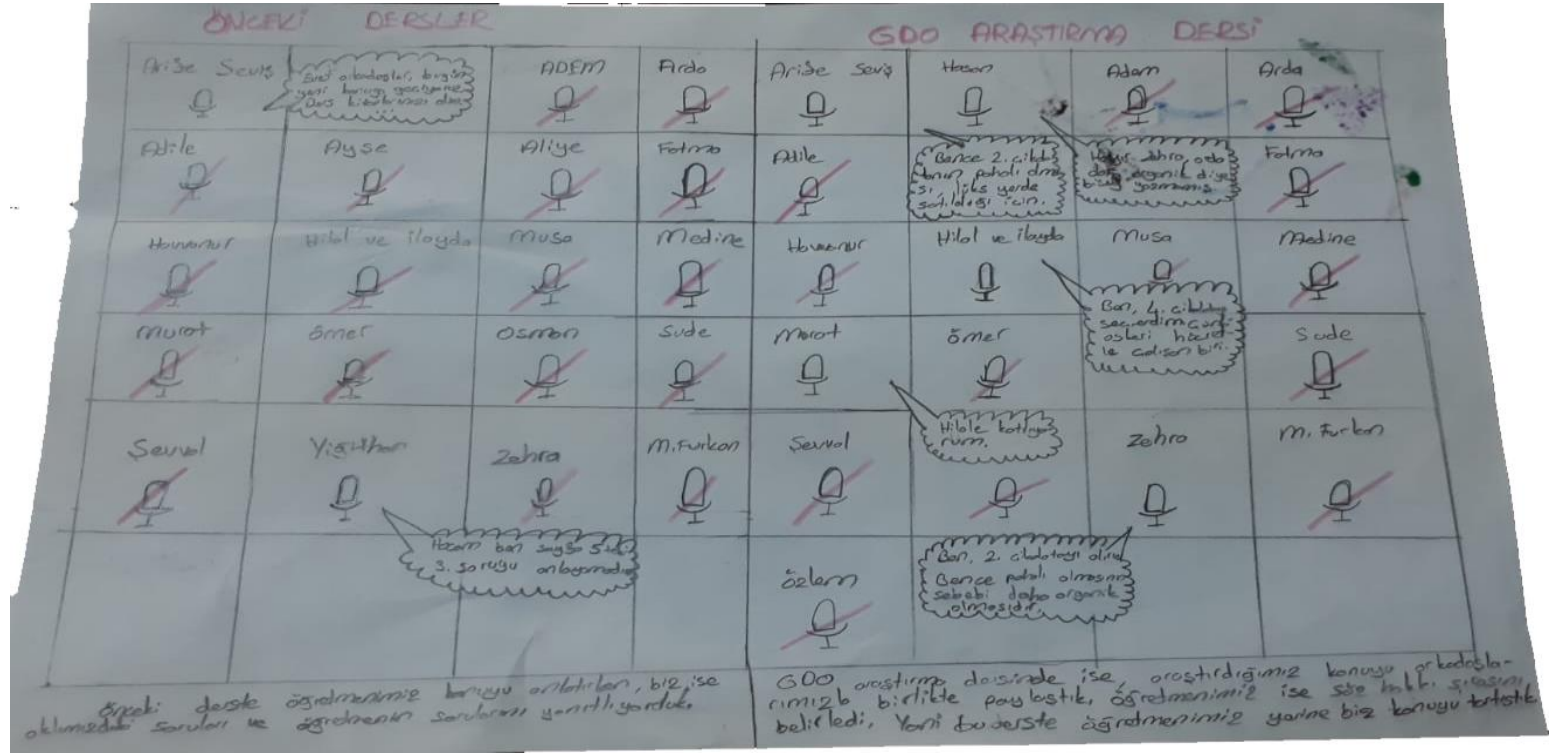

Şekil 2. A2'nin diyalojik öğretimle işlenen ders ile daha önceki dersleri karşılaştıran resmi

Şekil 2'de verilen A2 çiziminde önceki derslere (solda) ilişkin öğretmeninin ve sadece bir arkadaşının mikrofonunu açık olarak çizmiştir. Diğer tüm öğrencilerin derste mikrofonları kapalıdır. Öğretmen, “Arkadaşlar bugün yeni konuya geçiyoruz kitaplarınızı açın!" derken, mikrofonu açık olan öğrenci "Ben sayfa 5' teki 3. soruyu anlamadım." demektedir. Öğretmen-öğrenci etkileşimi bu konuşmaya dayalıdır. Açıklamasını da "Önceki derslerde öğretmen konuyu anlatıyor, biz ise aklımızdaki soruları ve öğretmenimizin sorduklarını cevaplıyorduk.” şeklinde yapmıştır.

GDO konusunda işlenen derse (sağda) ilişkin çizim ve açıklamasında öğretmen ve beş öğrencinin mikrofonları açık olarak çizilmiştir. Konuşan öğrencilerden biri "Ben 4. çikolatayı seçerdim çünkü asgari ücretle çalışan biri”" derken diğeri "Hilal'e katılıyorum" bir diğeri ise "Ben 2. çikolatayı seçerdim çünkü pahalı olmasının sebebi organik olması" şeklinde görüş belirtmektedirler. Dolayısıyla daha fazla öğrencinin derste konuştuğuna ve öğrencilerin görüşlerinin de farklılaştığına dikkat çekmiştir. Açıklamasını da “GDO'lu dersimizde araştırdığımız konuyu arkadaşlarımızla birlikte paylaştık öğretmenimiz ise söz hakkı sıralamamızı belirledi. Yani bu derste öğretmenimiz yerine biz konuyu tartıştık.” şeklinde görüşünü yazmıştır. 


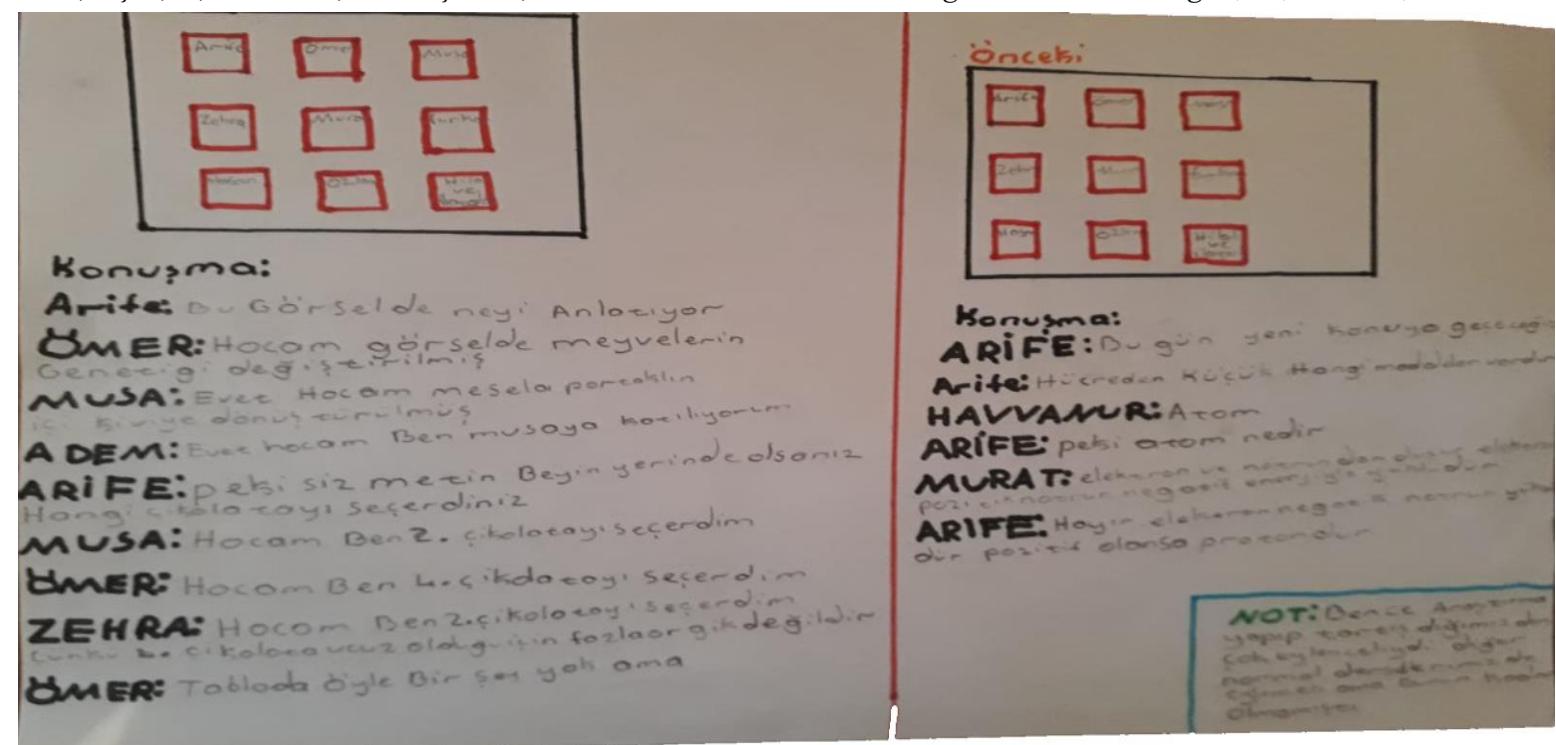

Şekil 3. A3'ün diyalojik öğretimle işlenen ders ile daha önceki dersleri karşılaştıran resmi

Şekil 3'de verilen A3 çiziminde önceki derslere (sağda) ilişkin öğretmenin kapalı uçlu sorusuna yönelik iki öğrenci ile yaptığ kısa etkileşimi ortaya koymuştur. Belirtmiş olduğu etkileşim kalıbı fen sınıflarında çok kullanıldığı görülen ve geleneksel öğretime işaret eden IR (Başlatma-yanıt) ve IRE (Başlatma-yanıt-değendirme) olarak geçen otoriter etkileşimli iletişimsel yaklaşımdır.

Diyalojik öğretime dayalı işlenen derse (solda) ilişkin çizim ve açıklamasında öğretmenin sınıfında verdiği senaryoya ilişkin farklı öğrencilerden aldığı görüşlere yer vermiştir. Yazmış olduğu notta öğrenci "Bence araştırma yapıp tartıştığımız bu ders daha eğlenceli diğer normal derslerimizde eğlenceli ama bunun gibi olmamıştı.” yorumunu yapmıştır. A3 öğrencisinin çiziminin altındaki açıklamalardan diyalojik öğretimin öğretmenöğrenci etkileşimini değiştirdiği ve dersi eğlenceli kıldığı anlaşılmaktadır.

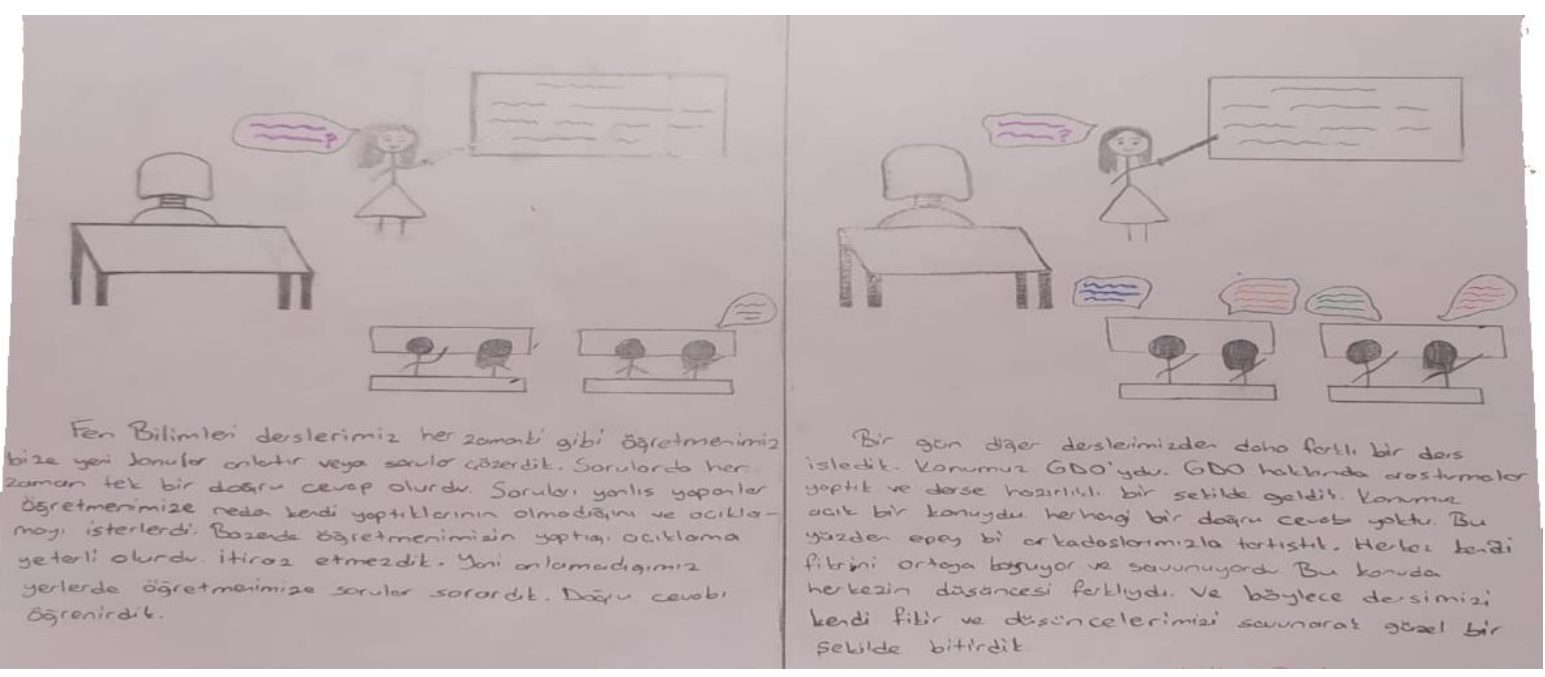


Şekli 4'de verilen A4 çiziminde önceki derslerde (solda) tek bir öğrencinin konuştuğu, GDO konusunda diyalojik öğretimle işlenen derste (sağda) dört öğrencinin de konuştuğunu konuşma baloncuklarıyla göstermiştir. A4 öğrencisin her zamanki ders olarak çizdiği soldaki resmin açıklamasını şu şekilde yazmıştır:

Her zamanki gibi öğretmenimiz bize konular anlatır veya sorular çözerdik. Sorularda her zaman tek bir cevap olurdu. Soruları yanlış yapanlar öğretmenimize neden kendi yaptıklarının olmadığını ve açıklamayı isterlerdi. Bazen de öğretmenimizin yaptığı açıklama yeterli olurdu, itiraz etmezdik. Yani anlamadığımız yerlerde öğretmenimize sorular sorardık. Doğru cevabı öğrenirdik" (Yazılı açıklama: A4).

A4 öğrencisi GDO’ya dayalı diyalojik öğretimle işlenen sağdaki resmin açıklanmasını şu şekilde yazmıştır

Diğer derslerimizden daha farklı bir ders işledik. Konumuz GDO’ydu. GDO hakkında araştırmalar yaptık ve derse hazırlıklı bir şekilde geldik. Konumuz açık bir konuydu, herhangi bir doğru cevabı yoktu. Bu yüzden epey bir arkadaşlarımızla tartıştık. Herkes kendi fikrini ortaya koyuyor ve savunuyordu. Bu konuda herkesin düşüncesi farklıydı ve böylece dersimizi kendi fikir ve düşüncelerimizi savunarak güzel bir şekilde bitirdik (Yazılı açıklama: A4).

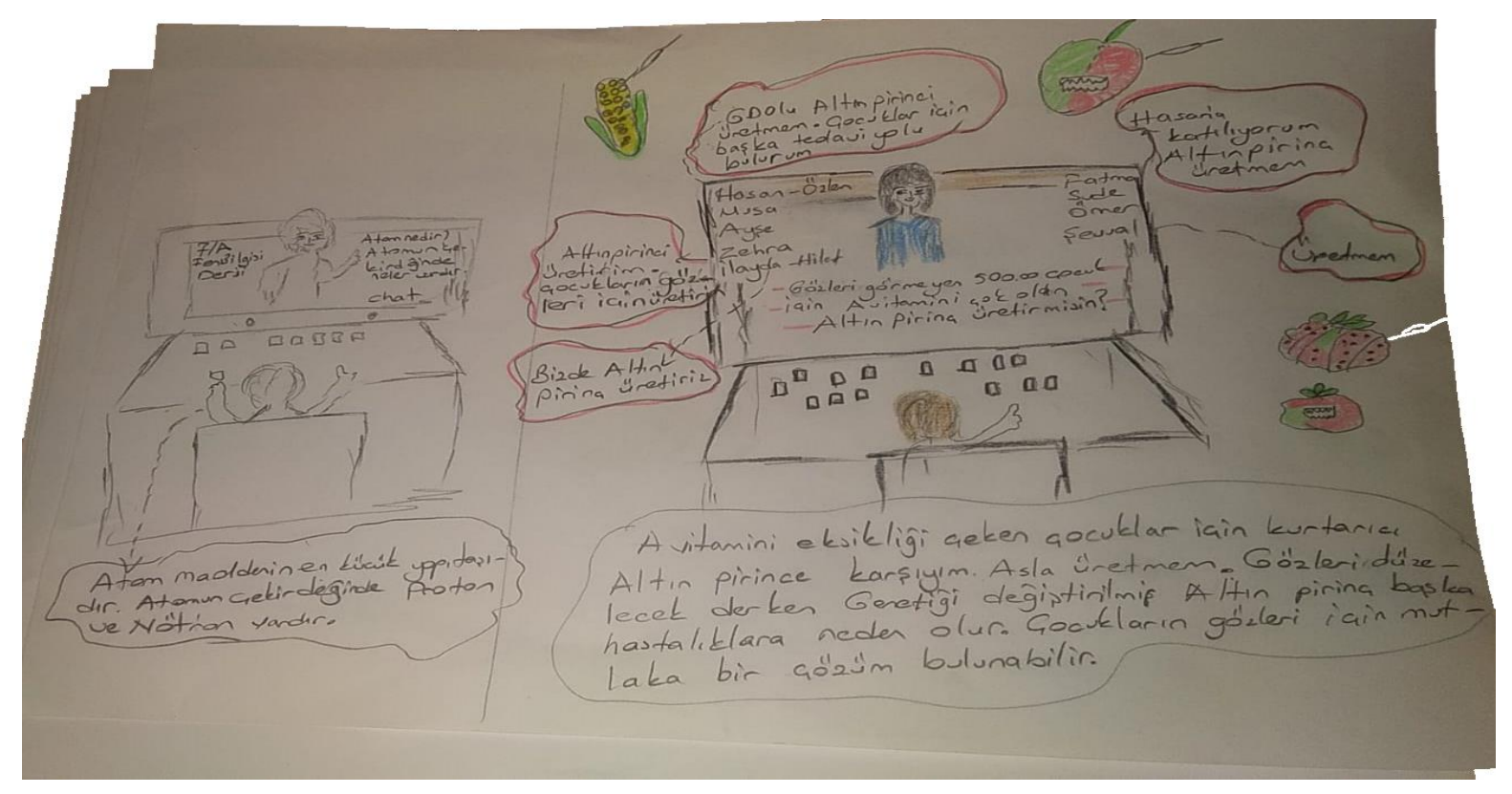

Şekil 5. A5'in diyalojik öğretimle işlenen ders ile daha önceki dersleri karşılaştıran resmi 
E, Uçak, A, S. Gencer, A.Seviş ve S, Usta/ Pamukkale Üniversitesi Eğitim Fakültesi Dergisi, 55, 294-323, 2022313

Şekil 5'de verilen A5 çiziminde önceki derslere (solda) ilişkin çizmiş olduğu resimde öğretmen “Atom nedir? Atomun çekirdeğinde neler vardır?” sorusunu sormakta, bir öğrenci ise "Atom maddenin en küçük yapıtaşıdır. Atomun çekirdeğinde proton ve nötron vardır." şeklinde cevap vermektedir.

GDO konusuna ilişkin diyalojik olarak işlenen derste (sağda) ise öğretmenin yanında sınıftaki öğrencilerin çoğunun adı yazmaktadır. Öğretmen, "Gözleri görmeyen 500.000 çocuk için altın pirinç üretir misiniz?” sorusunu sormaktadır ve öğrencilerin görüşü konuşma baloncuklarıyla açıklanmaktadır. Resmin altına da açıklama olarak "A vitamini eksikliği çeken çocuklar için kurtarıcı altın pirince karşıyım. Asla üretmem. Gözleri düzelecek derken genetiği değiştirilmiş altın pirinç başka hastalıklara neden olur. Çocukların gözleri için mutlaka başka bir çözüm bulunabilir.” yazmıştır.

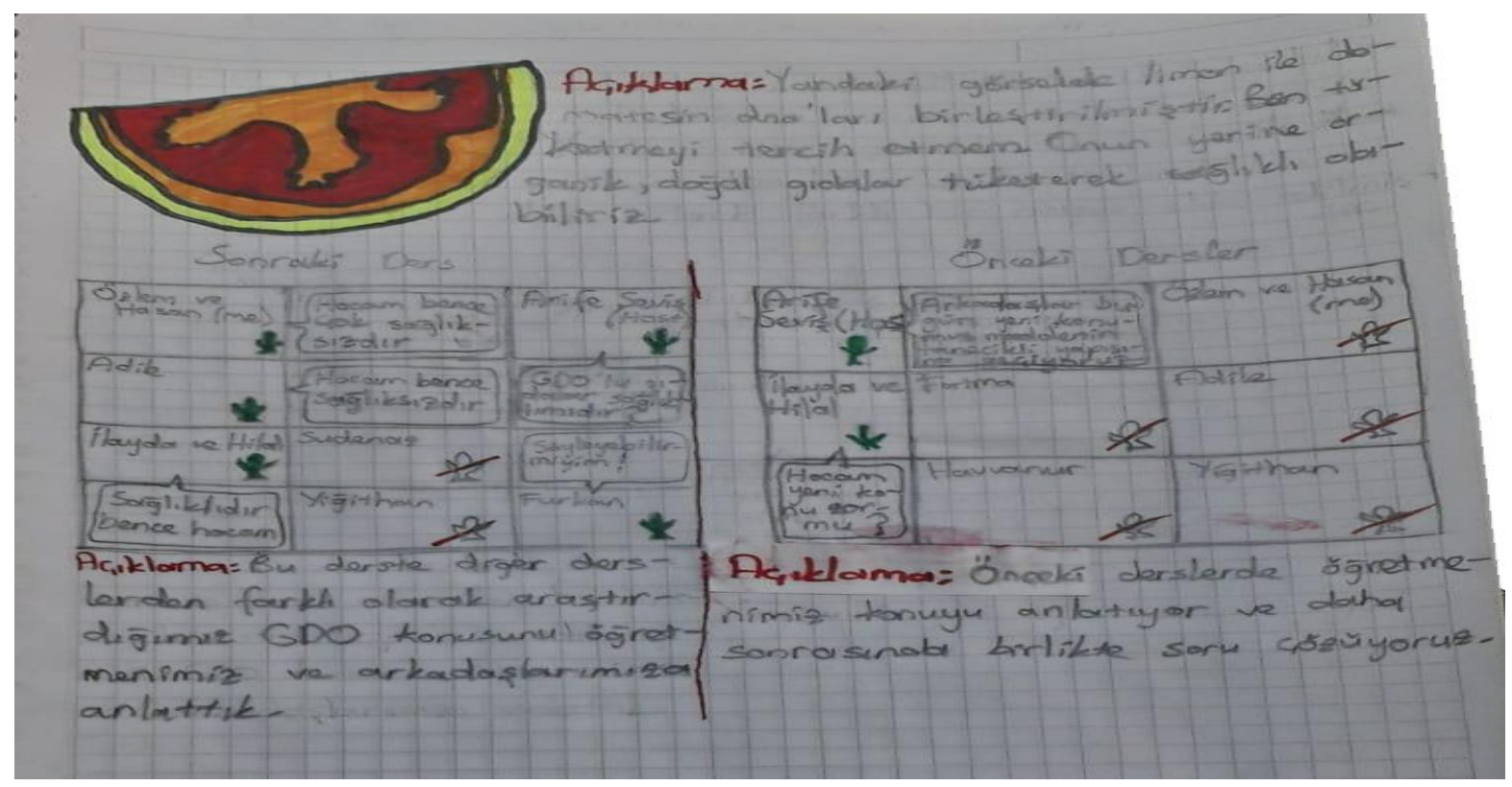

Şekil 6. A6'nın diyalojik ögretimle işlenen ders ile daha önceki dersleri karşılaştıran resmi

Şekil 6' da verilen 6 önceki derslere ilişkin (sağda) çiziminde öğretmeninin ve sadece bir arkadaşının mikrofunu açıktır. Diğer tüm öğrencilerin derste mikrofonu kapalıdır. Resimde öğretmen derste işleyecekleri konuyu söylerken mikrofonu açık olan öğrenci de “Öğretmenim konu zor mu?” diye sormaktadır. Öğretmen-öğrenci etkileşimi bu konuşmaya dayalıdır. Açıklamasını da "Önceki derslerde öğretmen konuyu anlatıyor ve daha sonrasında birlikte sorular çözüyoruz.” şeklinde yapmıştır.

GDO konusuna ilişkin diyalojik olarak işlenen derse ilişkin (solda) çiziminde sadece iki arkadaşının mikrofonu kapalıyken sınıftaki diğer öğrencilerin tümünün mikrofonu açıktır. Konuşan öğrencilerden de büyük bir çoğunluğu GDO ya ilişkin "sağlıksız" derken, 
bir öğrenci "sağlıklıdır" yanıtını vermiştir. Dolayısıyla daha fazla öğrencinin derste konuştuğuna dikkat çekmiştir. Açıklaması da "Bu derste diğer derslerden farklı olarak araştırdığımız GDO konusunu öğretmenimiz ve arkadaşlarımıza anlattık.” şeklindedir.

\section{Tartışma, Sonuç ve Öneriler}

$\mathrm{Bu}$ çalışmada, sosyobilimsel bir konu olan GDO konusunda gerçekleşen diyalojik öğretim ortamına ilişkin olarak öğrenci görüşleri alınmış ve öğrencilerden daha önce işlenen fen dersleri ile diyalojik öğretimin yapıldığı derse ilişkin görsel modellemelerini resim çizerek açıklamaları istenmiştir. Öğrenci katkılarının değerli görüldüğü diyalog biçiminde gerçekleşen diyalojik öğretim uygulamaları, sosyobilimsel konularla ilgili öğrencilerin bakış açılarını ifade etmesi ve başkalarının bakış açılarını görme ve onlar hakkında düşünme fırsatlarını öğrencilere sunması açısından önemlidir (Ratcliffe ve Grace 2003; Zeidler, Sadler, Applebaum ve Callahan, 2009). Öğrencilerin bakış açılarını dikkate alan ve onları etkileşimli bir biçimde sürece dahil eden diyalojik sınıf uygulamalarının ortaya çıkması, fen öğretmenlerinin üzerine yeni sorumluluklar yüklemektedir. Çünkü fen öğretmenlerinin çoğu, tartışmaları yönetmek için gerekli olan öğretme stratejilerine sahip değildirler (Bryce ve Gray, 2004). Bu bağlamda çalışmadan önce oldukça otoriter söylemleri dersinde kullandiğı görülen bir fen öğretmenine 12 hafta boyunca diyalojik öğretime yönelik eğitimler verilmiştir. Araştırmalar, öğrencilerin katkılarının öğretmen tarafından dikkate alınmasının sınıf söylemine öğrencilerin katılımını ve ilgisini desteklediğini işaret etmektedir (Nystrand, 1997; Smith and Higgins, 2006). Öğrencilerin katkılarının önemsendiği, öğretmenin öğrenci katkılarının etkileşimlerin yönünü değiştirmesine ya da öğrencilerin fikirlerinin sonraki tartışmalara yön vermesine veya bir öğrenci tarafından ortaya konulan yeni bakış açılarının daha detaylı ele alınmasına izin vermesi ile gösterilebilir (Nystrand, 1997). Böylece öğrenciler sınıf söyleminin meşru katılımcıları olarak konumlandırılır. Çalışmada da öğrencilerin görüşme bulguları incelendiğinde; özellikle sınıf içi konumlandırmalarına ilişkin görüşmeye katılan tüm öğrenciler diyalojik öğretim yapılan derslerde öğretmenlerini kutup yıldızına yani rehbere benzetmişler, kendilerini ise fikirlerini özgürce söyleyip savunan, araştıran derse aktif katılan katılımcılar olarak konumlandırmışlardır.

Yine çizilen resimlerde de öğrencilerin sosyobilimsel bir konu olan GDO konusunda diyalojik öğretimle işlenen derslerde kendilerini daha aktif ve derse daha çok katılan olarak konumlandırdıkları görülmüştür. Han Tosunoğlu ve İrez’e (2019) göre, “SBK öğretimini gerçekleştirecek bir öğretmen diyaloğa dayalı öğretim yaklaşımını benimsemiş, SBK ile ilgili alan bilgisine sahip, sınıf içinde öğretmen merkezli yaklaşımdan çok öğrenci merkezli 
E, Uçak, A, S. Gencer, A.Seviş ve S, Usta/ Pamukkale Üniversitesi Eğitim Fakültesi Dergisi, 55, 294-323, 2022315 bir yaklaşım sergileyen" (s.395), dolayısıyla "sınıfta kendini bir otoriteden çok tartışmaya katkı sağlayan biri olarak konumlandırmalıdır” (s. 393). Bu bağlamda öğrencilerle yapılan görüşmelerde öğretmen-öğrenci konumlandırmaları öğrenci merkezli yaklaşıma işaret etmektedir. Çalışmaya katılan tüm öğrencilerin diyalojik öğretimle işlenen derslere ilişkin resimlerinin açıklamalarında kendilerine otorite tarafından dikte edilen ifadeler yerine kendi seçimlerini yansıtabilmeleri sınıf söylemlerinde yer aldıkları bir öğrenme ortamın oluştuğunu göstermektedir. Sınıf içi tartışmalardaki seslerin çeşitliliğinin öğrenci özerkliği ile sağlanabileceğine dikkat çeken Karahan'a (2021) göre, "faillik kavramının sınıf içi söylemlerde belirginleşmesi sosyobilimsel konular özelinde fen okuryazarlı̆̆ hedefine ulaşılmasında dikkate değer bir öneme sahiptir (s. 45).

Araştırmaya katılan tüm öğrenciler diyalojik öğretimde sınıf normları açısından; öğretmenleri tarafından soruları cevaplamada yeterli düşünme zamanının tanındığını ve sorular hakkında yeterli konuşma süresi aldıklarını belirtmişlerdir. Öğretmen-öğrenci etkileşimlerinde öğretmenler öğrencilerden gelecek cevaplar için yeterli bekleme süresi tanımalıdır. Yeterli bekleme süresinin tanınması öğrencilerin düşünmelerine olanak tanımanın yanında, daha uzun ve gerekçeli cümleler kurmalarına, cevaplardaki çeşitliliğin artmasına ve analiz ve sentez basamağına yönelmelerine olanak tanımaktadır (Ingram ve Elliott, 2014). Yine tüm öğrenciler öğretmenin kendilerine eşit söz hakkı verdiğini ve düşünce ve fikirlere saygı duyduğunu belirtmiştir. Bazı öğrenciler ise demokratik, adil ve özgür sınıf ortamının onlara sağlandığına dikkat çekmiştir. Han Tosunoğlu ve İrez (2019) "SBK öğretimi için işbirlikçi, demokratik ve bireylerin birbirlerinin fikirlerine sayg1 duyduğu bir öğrenme ortamının” (s.399) oluşmasının önemli olduğunu belirtmiştir. Görüşme yapılan tüm öğrenciler farklı fikirlerin paylaşılıp tartışıldığı bir ortam oluştuğuna dikkat çekerken, bazıları fikirlere müdahale edilmemesine, arkadaşlarıyla tartışarak öğrenmeye ve derste bilimsel anlamda tek bir cevap aranmadığına vurgu yapmıştır.

Görüşmeye katılan tüm öğrenciler diyalojik öğretime dayalı işlenen dersin eğlenceli ve ilgi çekici olduğunu belirtirken dersin bu şekilde işlenmesinin onlarda merak, ilgi ve istek oluşturduğunu ifade etmiştir. Smit, Brabander ve Matens'in (2014) çalışma bulgularına göre; öğrenciler öğrenme ortamlarında etkili bir role sahip olmaları durumunda öğrenme adına daha fazla çaba sarf etmekte ve daha yüksek bir haz duygusuyla öğrenme sürecine dahil olmaktadırlar. Yine Cornelius-White'ın (2007) yaptığı çalışmada öğrencilerin öğrenmenin merkezinde yer aldığı yaklaşımların öğrenci katılımını, motivasyonunu, öz saygısını ve sosyal etkileşimini arttırdığı ortaya konmuştur. Diğer taraftan iki öğrenci ise 

arkadaşları kendilerinin fikirlerine katılmadıklarında üzüldüklerini bunun da onlarda olumsuz bir duygu oluşturduğunu ifade etmişlerdir. $\mathrm{Bu}$ durumun da muhtemelen öğrencilerin böyle bir durumla ilk kez karşılaşmış olduklarından ve alışık olmadıkları bir durum olmamasından kaynaklanmış olabileceği düşünülmüştür.

Görüşmeye katılan bazı öğrenciler diyalojik öğrenme ortamında oluşan birtakım unsurları beğenmediklerini dile getirmişlerdir. Öğrenciler, zaman zaman hep bir ağıdan konuşulmasına ve konuşmaların anlaşılmamasına, fikirlere zaman zaman akranları tarafından müdahale edilmesine ve ders süresinin yetersiz olduğuna dikkat çekmiştir. Diyalojik öğretim yapıldığı sınıflarda özellikle konuşma kurallarının oturması zaman alabilmektedir. Cobb, Gravemeijer, Yackel, McClain ve Whitenack (1997) çağdaş öğretim yaklaşımlarının değer verdiği becerilerin kazandırılmasına yönelik normların oluşturulması gerektiği, buna ters düşen normların ise terk edilmesi gerektiği yönünde uğraş göstermek üzere sınıf içi normlar kavramı üzerine yoğunlaşmışlardır. Özmantar, Bingölbali, Demir, Sağlam ve Keser (2009), sınıf içi normları şu şekilde özetlemişlerdir; düşüncelerin açıklanması, düşüncelerin gerekçelerinin sunulması, bütün öğrencilerin çekinmeden fikirlerini paylaşmaları, sınıfta paylaşılan tüm düşüncelerin öğrenciler tarafından anlaşılmaya çalışılması, bütün öğrencilerin yapılan çalışmalara katılıp katılmadıklarını belirtmesi, farklı açıklamalar üretilmesi, açıklamaların doğruluğunun sorgulanması şeklindedir.

Diyalojik öğrenme ortamında öğrenci-öğrenci etkileşimi çerçevesinde görüşmeye katılan öğrencilerden yarısı akranlarının konuyla ilgili görüşlerinin onların fikirlerini etkilemediklerine yani yine kendi argümanlarını savunduklarını belirtirken diğer yarısı arkadaşlarının argümanlarını duyduklarında fikirlerinde değişim olduklarını dile getirmişlerdir. Görüşmeye katılan öğrencilerin çizimleri ve yorumları incelendiğinde ise; öğretmenin önceki fen derslerinde otoriter yaklaşımları kullanarak öğrencilerin akranları ile etkileşime geçmelerine yeterince imkân tanınmadığı görülmüştür. Bulgular Tsai (2002) tarafından yapılan sınıflandırmada ortaya konulan geleneksel öğretmenlerin özellikleri ile örtüşmektedir. Bu sınıflandırmada geleneksel öğretmenlerin fen öğretimine bakışı ve uygulamaları şu şekilde değerlendirilmiştir: Fen en iyi, öğretmenden öğrenciye bilgi aktarımıyla gerçekleşir. Bu bakış açısını doğrulayıcı davranışlar ise şunlardır: Bilgi aktarımı; ilk cevabı verme; belli, net tanımlamalar yapma; kesin, doğru açıklamalar verme, bilimsel gerçekler veya olguları sunma şeklindedir. Literatür incelendiğinde, Akış (2012) tarafından, otoriter ve diyalojik söylemin ortaya çıktığı sınıf ortamları karşılaştırılarak aralarındaki 
E, Uçak, A, S. Gencer, A.Seviş ve S, Usta/ Pamukkale Üniversitesi Eğitim Fakültesi Dergisi, 55, 294-323, 2022317 farkl1lıklar ortaya konmaya çalışılmıştır. Otoriter öğretmene göre öğretmen, bilginin kaynağı; öğrenci ise doğruyu bulmaya çalışan ve öğretmeni onaylayan kişidir. Diyalojik öğretmene göre öğretmen ise, öğrencilerin farklı fikirlerini önemseyen, onları dinleyen, yargılamayan ve yeni fikirler üretmeleri için onları cesaretlendiren; öğrenci ise fikir üreten, başkalarının fikirlerini önemseyen, dinleyen ve tartışan kişidir. Yine tüm resimler otoriter ve diyalojik öğrenme ortamlarını bu açıdan çok net olarak ortaya koymaktadır. Buna ek olarak bazı çizimler (Şekil 3 ve Şekil 5) fen öğretimi sırasında öğretmenlerin kullandıkları sorular gözlemlendiğinde genelde düşük bilişsel seviyeli sorular kullandıkları tespit edilmiştir. Oysaki Yılmaz'a (2017) göre, üretken öğretmen konuşmaları öğrenciyi muhakemeye yöneltirken derin olmayan sorular kısa cevaplı, doğru yanlış türündeki cevapların verilmesine neden olduğundan öğrencinin cevabını sınırlandırır ya da cevap alınamamasına neden olur.

Sınıf içi söylemleri araştıran çalışmalar fen eğitiminde önem kazanmaktadır. Yıldırım, Uçak ve Savran Gencer (2021) tarafından yapılan çalışmada sınıf içi konuşmalara dayalı yayınların özellikle Web of Science' da diğer alan indeksli dergilere göre daha fazla yayınlandığı ve bu alanda yapılan çalışmalarının sayısının gün geçtikçe arttığı ortaya konmuştur. Sınıf içi konuşmalardan özellikle diyalojik öğretime dayalı yayınların da sayısı dikkat çekmektedir. Ancak ülkemiz açısından bakıldığında Ulakbim ve tez çalışmaları incelendiğinde diyalojik öğretime ilişkin çalışmalar çok sınırlıdır.

Çalışma sosyobilimsel konuların öğretimi açısından değerlendirildiğinde; SBK'nın doğası gereği öğretim ortamının diyalojik ve yansıtıcı olması gerekmektedir (Lee vd., 2013). Saunder ve Rennie'nin de (2013) SBK öğretiminin didaktik ve öğretmen merkezli bir yaklaşım ile mümkün olamayacağını ve SBK öğretim sürecindeki sorgulamanın bir karar vermekten çok farklı bakış açılarının farkına varılmasını sağlamak olduğunu vurgulamaktadır. Yine Sadler'ın (2011) SBK öğretimi için ortaya koyduğu modelde sınıf ortamının önemli olduğu, öğrenci ve öğretmenin kendini sınıf ortamında güvende ve demokratik bir ortamda hissetmesi gerektiği vurgulanmaktadır. Dolayısıyla öğretmenlerden herkesin fikirlerini açıkça ortaya koyacağı demokratik ve açık fikirli bir sınıf ortamı oluşturmaları beklenmektedir. SBK sınıflarında, öğrenciler, öğrenmelerinin işbirliği ve epistemolojik anlayışların karşılıklı olarak şekillendirilmesi yoluyla ilerlemesine izin veren çeşitli söylem biçimlerine katılmaya teşvik edilmelidir.

Kanadlı (2012) ile Uçak (2014) çalışmalarından elde edilen bulgular da öğretmenlere ve öğretmen adaylarına eğitim verildiğinde eğitimler sonunda diyalojik söylemleri 

sınıflarına entegre edebildikleri görülmüştür. Bu bağlamda çalışmada öğretmen ve öğretmen adaylarına diyalojik öğretime yönelik farkındalık oluşturmak amacıyla eğitimlerin verilmesi gerektiği önerilmektedir. Diyalojik öğretime ilişkin öğretmen deneyimlerini yansıtan çalışmalar yapılabilir. Ayrıca çalışma diyalojik öğretime dayalı ders işlenen sınıflarda öğrenci gözüyle bakış açısını ortaya koyan ilk çalışmadır. Dolayısıyla daha fazla çalışma yapılıp öğrenci gözüyle sınıf içi uygulamalar ortaya konulabilir. Özellikle Hajhosseiny (2012) tarafından yapılan çalışmada sokratik diyaloğun uygulandığı gruptaki öğrencilerin eleştirel düşünme ve sosyal iletişim (örn. birbirlerini tanıma, dostluk ve samimiyet, diyalog eğilimi, sorumluluk, sınıf dinamizmi, öğretmenle iletişim, eğitmenle olan samimiyet) becerilerinde gelişme olduğu tespit edilmiştir. Bu tür üst düzey becerilere ait özelliklerin gelişmesi için de sınıflarda diyalojik öğretimin önemli olduğu düşünülmektedir. Dolayısıyla tüm bu unsurlar da farklı çalışmalarda irdelenebilir.

Etik Kurul İzin Bilgisi: Bu araştırma, Pamukkale Üniversitesi Sosyal ve Beşeri Bilimleri Bilimsel Araştırma ve Yayın Etiği Kurulunun 25/02/2021 tarihli 68282350/2018/G04 sayılı kararl ile alınan izinle yürütülmüşı̈̈r.

Yazar Çıkar Çatışması Bilgisi Makalenin yazarları arasında çıkar çatışması yoktur.

Yazar Katkısı: Araştırmanın tüm aşamalarında yazarlar eşit katkı vermiştir.

\section{Kaynakça}

Akış, A. (2012). Otoriter ve diyalojik öğretmenlerin ögrretmen-öğrenci rollerine dair beklenti ve inançları. Yayınlanmamış yüksek lisans tezi. Gaziantep Üniversitesi, Gaziantep.

Aleaxander, R. (2006). Towards dialogic teaching: Rethinking classroom talk. Cambridge: Dialogos.

Almahrouqi, A. \& Scott, P. (2012). Classroom discourse and science learning. In D. Jorde \& J. Dillon (Eds.), Science education research \& practice in Europe: Retrospective and prospective (pp. 291-307). Rotterdam, Netherlands: Sense publishers.

Billings, L. \& Fitzgerald, J. (2002). Dialogic discussion and the Paideia Seminar. American Educational Research Journal, 39(4), 907-941. https://doi.org/10.3102/00028312039004905 
E, Uçak, A, S. Gencer, A.Seviş ve S, Usta/ Pamukkale Üniversitesi Eğitim Fakültesi Dergisi, 55, 294-323, 2022319

Bryce, T. \& Gray, D. (2004). Tough acts to follow: The challenges to science teachers presented by biotechnological Progress. International Journal of Science Education, 26(6), 717-733. https://doi. org/10.1080/0950069032000138833

Chin, C. (2006). Classroom interaction in science: Teacher questioning and feedback to students' responses. International Journal of Science Education, 28 (11), 1315-1346.

Cobb, P., Gravemeijer, K.P.E., Yackel, E., McClain, K., \& Whitenack, J.W. (1997). Mathematizing and symbolizing: The emergence of chains of signification in one firstgrade classroom. In: D. Kirschner \& J. Whitson (Eds.), Situated cognition theory: Social, semiotic, and neurological perspectives (pp. 151-233). Mahwah, NJ: Lawrence Erlbaum Associates.

Corden, R. (2009). Literacy and learning through talk. Open University Press.

Cornelius-White, J. (2007). Learner-centered teacher-students relationships are effective: A meta-analysis. Review of Educational Research, 77, 113-143.

https://doi.org/10.3102/003465430298563.

Çepni, S., (2007). Araştırma ve proje çalışmalarına giriş. Trabzon: Celepler Matbaacılık.

Game, A. \& Metcalfe, A. (2009). Dialogue and team teaching. Higher Education Research \& Development, 28(1), 45-57.

Hajhosseiny, M. (2012). The effect of dialogic teaching on students' critical thinking disposition. Procedia- Social and Behavioral Sciences, 69, 1358 - 1368.

Han Tosunoğlu, Ç. \& İrez, S. (2019). Sosyobilimsel konuların öğretimi için pedagojik bir model. Yükseköğretim ve Bilim Dergisi/Journal of Higher Education and Science, 9(3), 384-401. https://doi.org/10.5961/jhes.2019.340.

Hofstein, A., Eilks, I., \& Bybee, R. (2011). Societal issues and their importance for contemporary science education - a pedagogical justification and the state-of-the-art in Israel, Germany, and the USA. International Journal of Science and Mathematics Education, 9(6), 1459-1483. https://doi.org/10.1007 /s10763-010-9273-9.

Ingram, J. \& Elliott, V. (2014). Turn taking and 'wait time' in classroom interactions. Journal of Pragmatics, 62, 1-12. DOI: 10.1016/j.pragma.2013.12.002 
E, Uçak, A, S. Gencer, A.Seviş ve S, Usta/ Pamukkale Üniversitesi Eğitim Fakültesi Dergisi, 55, 294-323, 2022

Kanadlı, S. (2012). Öğretmenlere yönelik hazırlanan bir mesleki gelişim programının etkililiğinin incelenmesi. Yayınlanmamış doktora tezi. Gaziantep Üniversitesi, Gaziantep.

Karahan, E. (2021). Sosyobilimsel konularda öğrenci failliği. D. Karışan ve A. Yenilmez Türkoğlu (Ed.), Sosyobilimsel Konular içinde (1.bask1 s. 31-48). Ankara: Eğiten Kitap Yayıncılık.

Kılınç, A., Demiral, U., \& Kartal, T. (2017). Resistance to dialogic discourse in SSI teaching: The effects of an argumentation-based workshop, teaching practicum, and induction on a preservice science teacher. Journal of Research in Science Teaching, 54(6), 764-789. https://doi.org/10.1002/tea.21385.

Kutnick, P. \& Colwell, J. (2010). Dialogue enhancement in classrooms. Towards a relations approach for group working. K. Littleton, C. Howe (Eds.), Educational dialogues: Understanding and promoting productive interaction (pp. 192-215). London: Routledge.

Lee, H., Yoo, J., Choi, K., Kim, S.-W., Krajic, J., Herman, B. C., \& Zeidler, D. L. (2013). Socioscientific issues as a vehicle for promoting character and values for global citizens. International Journal of Science Education, 35(12), 2079-2113.

Levinson, R. (2004). Teaching bioethics in science: Crossing a bridge too far? Canadian Journal of Science. Mathematics and Technology Education, 4(3), 353-369. https://doi.org/10.1080/14926150409556619

Levinson, R., Douglas, A., Evans, J. E., Kirton, A., Koulouris, P., Turner, S., \& Finegold, P. (2001). Valuable lessons: engaging with the social context of science in schools [report]. Wellcome Trust, London.

Lyons, T. (2006). Different countries, same science classes: Students' experiences of school science in their own words. International Journal of Science Education, 28(6), 591613. https://doi.org/10.1080/09500690500339621.

Mercer, N. \& Littleton, K. (2007). Dialogue and the development of children's thinking: A sociocultural approach. UK: Routledge, London.

Miles, M. B. \& Huberman, A.M. (1994). Qualitative data analysis (2nd ed.). CA: Sage, Thousand Oak. 
E, Uçak, A, S. Gencer, A.Seviş ve S, Usta/ Pamukkale Üniversitesi Eğitim Fakültesi Dergisi, 55, 294-323, 2022321

Mortimer, E.F. \& Scott, P.H. (2003). Meaning making in secondary science classrooms. Open University Press, Maidenhead/Philadelphia.

Nystrand, M. (1997). Opening dialogue: Understanding the dynamics of language and learning in the English classroom. New York, NY: Teachers College Press.

Nystrand, M., Gamoran, A., Kachur, R., \& Prendergast, C. (1997). Opening dialogue. Understanding the Dynamics of language and learning in the English classroom. New York, London: Teachers College Press.

Nystrand, M., Wu, L.L., Gamoran, A., Zeiser, S., \& Long, D.A. (2003). Questions in time: Investigating in the structure and dynamics of unfolding classroom discourse. Discourse Processes, 35(2), 135-198.

Osborne, J., Duschl, R., \& Fairbrother, R. (2002). Breaking the mould? Teaching science for public understanding. London, UK: Nuffield Foundation.

Özmantar, M.F., Bingölbali, E., Demir, S., Sağlam, Y. ve Keser, Z. (2009). Değişen öğretim programları ve sınıf içi normlar. Uluslararası Insan Bilimleri Dergisi, 6(2). http://www.insanbilimleri.com

Ratcliffe, M. \& Grace, M. (2003). Science education for citizenship: Teaching socioscientific issues. Maidenhead, UK: Open University Press.

Ratcliffe, M. \& Millar, R. (2009). Teaching for understanding of science in context: Evidence from the pilot trials of the "twenty first century science" courses. Journal of Research in Science Teaching, 46(8), 945-959. https://doi.org/10.1002/tea.20340.

Resnick, L. B., Asterhan, C. S. C., \& Clarke, S. N. (Eds.) (2015). Socializing intelligence through academic talk and dialogue. Washington, DC: American Educational Research Association.

Reznitskaya, A. \& Gregory, M. (2013). Student thought and classroom language: Examining the mechanisms of change in dialogic teaching. Educational Pschologist, 48 (2), 114-133. https://doi.org/10.1080/00461520.2013.775898

Sadler, T. D. (2011). Socio-scientific issues-based education: What we know about science education in the context of SSI. In T. D. Sadler (Ed.), Socio-scientific issues in the classroom: Teaching, learning and research (pp. 355-369). Dordrecht, The Netherlands: Springer. https://doi.org/10.1007/978-94-007-1159-4_20. 
Saunders, K.J. \& Rennie, L.J. (2013). A pedagogical model for ethical inquiry into socioscientific issues in science. Research in Science Education, 43(1), 253-274. DOI 10.1007/s11165-011-9248-z.

Scott. P.H, Mortimer, E.F., \& Aguiar. O.G. (2006). The tension between authoritative and dialogic discourse: A fundamental characteristic of meaning making interactions in high school science lessons. Science Education, 90, 605-631.

Scott, P., \& Ametller, J. (2007). Teaching science in a meaningful way: Striking a balance between 'opening up' and 'closing down' classroom talk. School Science Review, 88 (324), 77-83.

Scott, P., Ametller, J., Mortimer, E., \& Emberton, J. (2010). Teaching and learning disciplinary knowledge. In K. Littleton, \& Ch Howe (Eds.). Educational dialogues. Understanding and promoting productive interaction (pp.289-303). London, New York: Routledge.

Smith, H. \& Higgins, S. (2006). Opening classroom interaction: the importance of feedback. Cambridge Journal of Education, 36(4), 485-502.

Smit, K., de Brabander, C.J., \& Martens, R. L. (2014). Student-centred and teacher-centred learning environment in pre-vocational secondary education: Psychological needs and motivation. Scandinavian Journal of Educational Research, 58(6), 695-712. https://doi.org/10.1080/00313831.2013.821090

Tidemand, S. \& Nielsen, J. A. (2017). The role of socioscientific issues in biology teaching: From the perspective of teachers. International Journal of Science Education, 39(1), 44-61. https://doi.org/10.1080 /09500693.2016.1264644.

Tsai, W. (2002). Social structure of "coopetition" within a multiunit organization: Coordination, competition, and intraorganizational knowledge sharing. Organization Science, 13(2), 179-190.

Ulu, H. (2017). Dördüncü sınıf fen ve teknoloji derslerinin diyalojik öğretim açısından analizi üzerine bir araştırma. Ana Dili Eğitimi Dergisi, 5(4), 608-626.

Uçak, E. (2014). Öğretmen adaylarının fen öğretiminde kullandıkları iletişimsel yaklaşım türleri. Yayınlanmamış doktora tezi. Pamukkale Üniversitesi, Denizli.

van der Veen, C., van Kruistum, C. \& Michaels, S. (2015). Productive classroom dialogue as an activity of shared thinking and communicating: A Commentary on Marsal, 
E, Uçak, A, S. Gencer, A.Seviş ve S, Usta/ Pamukkale Üniversitesi Eğitim Fakültesi Dergisi, 55, 294-323, 2022323

Mind, Culture, and Activity, 22(4), 320-325. http://dx.doi.org/10.1080/10749039.2015.1071398

van Zee, E.H., Iwasyk, M., Kurose, A., Simpson, D., \& Wild, J. (2001). Student and teacher questioning during conversations about science. Journal of Research in Science Teaching, 38, 159-190.

Yıldırım, A. ve Şimşek, H. (2006). Sosyal bilimlerde nitel araştırma yöntemleri (6.Baskı). Ankara: Seçkin Yayıncılık.

Yıldırım, L., Uçak, E. ve Savran-Gencer, A. (2021). Fen derslerinde sınıf içi konuşmalar üzerine sistematik bir derleme. Trakya Eğitim Dergisi, 11(3), 1148-1172.

Yılmaz. Ş. (2017). Fen bilgisi öğretmenlerinin soru üretme hakkındaki muhakemeleri ve inanç sistemleri. Yayınlanmamış doktora tezi. Uludağ Üniversitesi, Bursa.

Zeidler, D. L., Sadler, T. D., Applebaum, S., \& Callahan, B. E. (2009). Advancing reflective judgment through socioscientific issues. Journal of Research in Science Teaching, 46(1), 74-101. https://doi.org/10.1002/tea.20281. 


\title{
Dialogic Teaching on GMOs as a Socio-scientific Issue from the Eyes of Students*
}

\author{
Esra UÇAK*, Ayşe SAVRAN GENCER**, Arife SEVIŞ***, Sibel USTA****
}

- Received: 28.11.2021 • Accepted: 03.02.2022 • First Online: 03.02.2022

\begin{abstract}
Although studies show that dialogic teaching is feasible and useful, the existing research has revealed that the authoritative discourse in which the teacher directs discussions tends to dominate. The current study investigated how students positioned themselves concerning the subject addressed in a dialogic learning environment. To this end, a science teacher, who was determined to have highly authoritative discourses, was asked to construct a dialogic lesson design on GMOs, a socioscientific issue, after 12 weeks of training on dialogic teaching and communicative communication approach. After the application, semi-structured interviews were conducted with six students to elicit their opinions about the delivered lessons. Moreover, the same six students were asked to compare the dialogically instructed lessons with their previous science lessons by means of drawings and to explain their drawings. In the findings, the student's opinions about the themes of teacher and student roles, classroom norms, learning environment, student characteristics, and student-student interaction in dialogic teaching were revealed, and the dialogic learning environment was interpreted on the basis of the students' drawings. When the data obtained from the student interviews were examined, especially for classroom norms, it was found that all students likened their teacher to the pole star; that is, a guide and positioned themselves as participants who freely talked about and defended their opinions, researched and actively participated in the lesson. When the drawings and explanations of the students were examined, it was determined that the teacher allowed students to express their opinions and thoughts in the lessons instructed dialogically compared to the previous lessons, and thus more student participation was achieved in the dialogically delivered lessons.
\end{abstract}

Keywords: dialogic teaching, socio-scientific issues, GMOs, science

\section{Cited}

Uçak, S., Gencer, A.S., Seviş, A.,\& Usta, S. (2022). Dialogic teaching on GMOs as a socio-scientific issue from the eyes of students. Pamukkale University Journal of Education, 55, 294-323. doi: 10.9779.pauefd. 1029432

\footnotetext{
*Assoc. Prof. Pamukkale University, Education Faculty, Department of Mathematics and Science Education, Denizli. ORCID: 0000-0003-2897-6462, eucak@ pau.edu.tr

**Assoc. Prof. Pamukkale University, Education Faculty, Department of Mathematics and Science Education, Denizli. ORCID: 0000-0001-6410-152X, asavran@pau.edu.t

***Non-thesis master's student, Pamukkale University, Institute of Educational Sciences, Program of Mathematics and Science Education, Denizli. ORCID: 0000-0001-5302-8152, arifesevis@gmail.com

**** Non-thesis master's student, Pamukkale University, Institute of Educational Sciences, Program of Mathematics and Science Education, Denizli, ORCID: 0000-0001-6436-9227, sibelusta2824@ gmail.com
} 


\section{Introduction}

Dialogue in the learning environment is seen as an exchange of ideas as a means of reconciliation and gaining knowledge that students could not acquire on their own previously (Game \& Metcalfe, 2009). In other words, individuals train themselves and other participants through the intense social interaction experienced in the dialogue process. Dialogue, therefore, has pedagogical potential. It takes its power from social interaction, which is also the basis of social constructivist philosophy. For this reason, researchers have used the concept of dialogic teaching with the conviction that learning and teaching also have a socio-cultural aspect (e.g., Alexander, 2006; Nystrand, Gamoran, Kachur \& Prendergast, 1997). Alexander (2006) states that spoken language plays a central role in teaching as it provides an opportunity to influence students' thinking processes through their involvement in classroom discourse and emphasizes that dialogic teaching uses this power of speech to engage students, activate and expand their thinking and improve their learning and understanding.

The most critical consideration in dialogic teaching is the extent to which students are given active roles as participants in constructing their knowledge base in classroom conversation (van Zee, Iwasyk, Kurose, Simpson, \& Wild, 2001). Therefore, the role of the teacher in dialogic teaching is to create an interactive space for students to talk and think together. In this way, the interaction begins between students (van der Veen, van Kruistum and Michaels, 2015), which supports discovering different views and understandings (Nystrand, Wu, Gamoran, Zeiser, \& Long, 2003). Other essential features of dialogic teaching are student autonomy and the fact that students are allowed, at least to some degree, to influence the course of events in the classroom (Reznitskaya and Gregory, 2013). Questioning in dialogic teaching that engages students in rich and stimulating discourse in a way that allows different voices to be heard deepens thinking and develops mental activity and higher-order thinking skills (Chin, 2006).

In connection with the classroom discourse, researchers have made definitions for the empirical study of the classroom discourse. A classroom discourse, in which a wide variety of ideas are represented, including students' perspectives, has been described as dialogic (Mortimer \& Scott, 2003; Nystrand, 1997). In contrast, the classroom discourse in which attention is focused on a particular point of view and ready-made information is conveyed is defined as authoritative by Mortimer and Scott (2003) and monologic by Nystrand (1997). The main feature of the authoritative discourse is the domination of the test 
questions whose answers have already been known by the teacher (Nystrand, 1997). In addition, authoritative discourse typically involves a clear assessment of students' contributions by the teacher (Scott, Mortimer \& Aguiar, 2006) and is often exhibited through an IRE pattern defined as teacher initiation — student response- teacher evaluation (Mortimer and Scott, 2003). In this way, the teacher exercises tight control over classroom discourse while being positioned as the primary source of knowledge. On the contrary, the essential feature of dialogic discourse is the use of genuine questions by the teacher (Scott et al., 2006). In other words, the feature of such questions is that they aim to reveal students' thoughts and that there is no direct teacher evaluation (Almahrouqi \& Scott, 2012; Scott \& Ametller, 2007; Scott et al., 2006). Instead, teachers use student contributions by integrating student responses into subsequent questions or focusing on perspectives put forward by students. In this way, students are positioned as important contributors to classroom discourse.

Dialogic teaching is attracting considerable attention in science education as it provides students with more opportunities to speak, make meaning and learn in fairer learning environments (Resnick, Asterhan \& Clarke, 2015). In science lessons, dialogic teaching can be understood as the interaction between the participants in the classroom and the teacher's management of the dialogue between different ideas (for example, everyday knowledge and scientific knowledge) (Mortimer \& Scott, 2003). Ulu (2017) emphasized that "the teaching process should be moved away from authoritative discourse, which focuses on a single view, where the boundaries of the content are drawn, the teacher directs the speech, and the student's ideas are ignored" (p. 623) in science lessons and stated that dialogic teaching should be preferred in classroom practices to combat authoritative teaching.

\section{The Significance of the Study in terms of Science Teaching}

Although studies are showing that dialogic teaching is feasible and useful (Billings \& Fitzgerald, 2002; Kutnick \& Colwell, 2010; Mercer \& Littleton, 2007; Scott, Ametller, Mortimer \& Emberton, 2010), the existing research has revealed that the authoritative discourse in which discussions are directed by the teacher with an emphasis on teaching science content tends to dominate (Hofstein, Eilks \& Bybee, 2011; K1lınç, Demiral \& Kartal, 2017; Levinson, 2004; Levinson et al., 2001; Osborne, Duschl \& Fairbrother, 2002; Ratcliffe \& Millar, 2009; Tidemand Nielsen, 2017) and thus, a little space is allocated to student perspectives in the classroom discourse (Lyons, 2006; Osborne et al., 2002). According to Corden (2009), this is probably because teachers did not encounter this type of 
E, Uçak, A.S. Gencer, A. Seviş, \& S. Usta / Pamukkale University Journal of Education, 55, 294-323, 2022297 teaching while they were students, and they did not receive any training on it in their preservice training.

When the literature is examined, it is seen that the studies mentioned above focus on teacher talk. However, no research has been found in which students' views on dialogic and authoritative classroom environments are investigated. However, students' views on dialogic teaching are also critical. In this regard, in the current study, a science teacher who was observed to have highly authoritative discourses as a result of the analysis of the recordings of whose previous lessons were instructed on dialogic teaching and then the opinions of the students on the dialogic lessons delivered by this teacher on the subject of genetically modified organisms (GMOs), a socio-scientific issue, were elicited and subsequently, the students were asked to explain their visual modeling about the previously delivered science lessons and the science lesson dialogically instructed on the subject of GMOs through drawings. Within the context of the current study, presenting dialogic content on GMOs will provide guidance to teachers in achieving GMO-related objectives addressed within the subject of biotechnology, a theme of science ethics in the course of Science Applications.

\section{Purpose of the Study}

In the current study, while dialogic teaching on a socio-scientific issue in science teaching was being carried out, an analysis of the lessons constructed on the basis of the communicative approach developed by Mortimer and Scott (2003) and dialogic discourses was performed from the eyes of the students. In the current study, which included a teacher who aimed to develop student participation and independence and make meaningful learning possible, the collected data were analyzed in terms of teacher-student interactions and the positioning of the students. In particular, how the teacher positioned the students in a dialogic learning environment and how they positioned themselves as participants in the classroom practices in relation to the subject being discussed were examined. In this connection, the following questions guided the study:

1. What are the students' opinions about the lesson carried out through dialogic teaching on GMOs as a socio-scientific issue?

2. What is the students' mental modeling about the lesson carried out through dialogic teaching on GMOs as a socio-scientific issue and the previous science lessons? 


\section{Method}

\section{Research Design}

The current study employed a qualitative research design. Qualitative research can be defined as "research in which qualitative data collection methods such as observation, interview, and document analysis are used, and a qualitative process is followed to reveal perceptions and events in a natural environment in a realistic and holistic manner" (Y1ldirim \& Şimşek, 2006, p. 39). A holistic single case study design was used in the current study since there was only one analysis unit consisting of students in a dialogic learning environment. The research was carried out in line with ethical principles with the approval of Pamukkale University Social and Human Sciences Scientific Research and Publication Ethics Committee with the decision dated 25/02/2021 and numbered 68282350/2018/G04.

\section{Study Group}

The science teacher of the purposefully selected study group has 14 years of professional experience and took the elective course Dialogical Teaching and Communicative Approach in Science Teaching within the scope of the non-thesis master's program of Pamukkale University. The course's main objective, which the first author conducted for three hours a week during an academic term, includes the use of dialogic teaching in the meaningful learning of science lessons targeting the course objectives in accordance with the secondary school science curriculum. After completing the course, the teacher of the study group wanted to create a lesson design based on dialogic teaching on the subject of GMOs as a socio-scientific issue and to conduct the lesson in that way. The teacher was invited to participate in the current study as she had chosen the course voluntarily and was seen to be quite authoritative in his previous lessons on socio-scientific issues and other science subjects. In line with the ethical principles of the study, the name of the teacher was kept confidential and coded as teacher A in the study.

The setting in which this study was carried out is a public secondary school with a low socio-economic level in the province of Denizli in the second term of the 2020-2021 school year. The study group is comprised of twenty $8^{\text {th }}$ grade students aged 13-14. After completing the application, semi-structured interviews were conducted with a total of six students from the teacher's class. Two of these students constantly preferred to participate in class activities, two of them preferred to participate from time to time, and two never preferred to participate, and the drawings of the same students were included in the study. In 
E, Uçak, A.S. Gencer, A. Seviş, \& S. Usta / Pamukkale University Journal of Education, 55, 294-323, 2022299

compliance with the ethical rules of the study, the students were coded as A1, A2, A3, A4, A5, and A6. Due to COVID-19, the lessons were conducted online. The students were invited to participate in the study in accordance with the ethical principles. The parent consent form was sent to the student's families, and they were asked to declare by signing whether or not they allowed their child to participate in the study. In this context, the students and families were informed about the general purpose of the study and the fact that their participation in the study should be on a volunteer basis. They were told that their names would be kept confidential and that they could leave the study whenever they wanted.

\section{Data Collection Tools}

Different data collection tools were used in the current study, including the video recordings of the classroom practices of the teacher, the interviews conducted with the students and the drawings produced by the students.

\section{Video recordings of the classroom practices}

In the study, the video recordings of the teacher's lessons were used in order to see the lessons of teacher $\mathrm{A}$ in terms of communicative approach before and during the study, teacher-student interaction, teacher-student role, that is, the positioning of the teacher and students in the classroom.

\section{Interview form}

As the data collection method, the semi-structured interview technique was used in the study. This technique is advantageous in that it allows asking in-depth questions on a specific topic and asking again if the answer is incomplete or unclear to make the situation more descriptive and complete the answers (Çepni, 2007). The audio recordings of the interviews conducted by one of the researchers with the participants were made with the consent of the participants. After the interviews, the audio recordings were transcribed. The interviews were carried out by adhering to an interview form prepared by the researchers. In order to develop the interview form, first, questions that could best reflect the determined purpose were developed. Clear and understandable questions were written in accordance with the purpose of the study. The semi-structured interview form was subjected to expert review. The prepared questions were given to two academicians who had studied this subject, and they were asked to analyze the questions; then, the form was finalized in light of the feedback provided by the experts. Moreover, the questions were asked to another student who was not in the study group, and the comprehensibility of the questions was checked. 
The questions that were deemed meaningless and unnecessary were removed from the form, and the interview form was given its final form. There is a total of 16 questions in the semistructured interview form.

\section{The drawings produced by the students}

The students were asked to compare the dialogically taught lessons on GMOs, a socioscientific issue, with the teacher's previous science lessons by drawing pictures and writing what the teacher and students are doing in the picture under the pictures they drew.

\section{Data Collection}

The data collection process is summarized below:

* Teacher A, who voluntarily participated in the study, presented the 4-week lesson videos that he had delivered and recorded online during the Covid-19 pandemic to the researchers before the training he would receive. Two of the researchers watched the recorded videos of the lessons and evaluated in terms of the communicative approach developed by Mortimer and Scott (2003).

* The teacher whose previous lessons were found to be delivered authoritatively and noninteractively and authoritatively and interactively was given training for 12 weeks on the following subjects: the constructivist approach theory and 5E model, social constructivism, dialogic teaching, communicative approach, discourse and discourse patterns, effective question asking strategies in the classroom, classroom norms, waiting times, investigation of the lesson designs based on dialogic teaching and meaningful learning of science subjects, the lesson design developed by Mortimer and Scott (2003) on the subject of corrosion, argumentation, techniques to support classroom communication such as concept cartoons, reading and interpreting articles written on the subject in the literature, watching lessons videos presenting the examples of dialogic teaching and the analysis of teacher-student, student-student communications in the videos at the micro-level.

* After completing the training, the teacher designed the lesson according to the biotechnology activity, which includes the subject of GMOs recommended being covered within six class hours in the curriculum under the theme of science ethics in the Course of Science Applications at the $8^{\text {th }}$-grade level. The teacher delivered his lessons through dialogical teaching based on the communicative approach proposed by Mortimer and Scott (2003) to ensure meaningful learning in science classes in such a 
E, Uçak, A.S. Gencer, A. Seviş, \& S. Usta / Pamukkale University Journal of Education, 55, 294-323, 2022301 way as to cover the discussion of the following objectives set in the curriculum: explaining the concept of GMO, researching how GMO products are obtained, evaluating how GMO products affect ecological balance and the economy of the country, evaluating GMO products in terms of global hunger problems, deciding on whether to consume GMO products or not and ethical issues related to GMO products.

* After the completion of the lessons, semi-structured interviews were conducted with a total of six students selected to include two students who constantly preferred to participate in the activities, two students who preferred to participate in the activities from time to time, and two students who never preferred to participate in the activities in the class. Moreover, the students were asked to compare the lessons dialogically taught and the science lessons previously delivered to them and to explain what they wanted to express in their drawings under the drawings.

\section{Data Analysis}

Content analysis, one of the qualitative data analysis techniques, was used in the analysis of the interview data. In content analysis, the data are analyzed in-depth, and in this way, previously unknown themes and codes are created. The basic process in content analysis is gathering similar data within the framework of certain concepts and themes and interpreting them by arranging them in a way that the reader can understand. While conducting a content analysis for this purpose, an inductive approach is followed (Yıldırım and Şimşek, 2006). The reliability of the study was calculated using Miles and Huberman's (1994) formula $[$ Reliability $=$ agreement $/($ agreement + disagreement $)]$. The code reliability was calculated to be $89 \%$. The drawings were interpreted.

\section{Findings}

\section{Findings Obtained from the Interviews Conducted with the Students}

The data obtained from the interviews conducted with the students were subjected to content analysis, and the findings obtained from this analysis are presented in Table 1.

Table 1. Themes and Codes Obtained from Semi-Structured Interviews

\begin{tabular}{lll}
\hline Themes & Codes & Students Mentioning \\
\hline Teacher-student & The role of the teacher in the class & \\
roles in the dialogic & Mirror (Reflecting information) & A1, A2, A3, A4, A5, A6 \\
teaching of a socio- & Pole star (A Guide) & \\
scientific issue & The role of the student in the class
\end{tabular}


Researching and actively participating in the A1, A3, A4, A5, A6 lesson

Freely expressing and defending his/her own A1, A2, A3, A4, A5, A6 ideas

Classroom norms in Timing

the dialogic teaching Enough time to think while answering

A1, A2, A3, A4, A5, A6

of a socio-scientific questions

issue

Enough time to talk about questions

A1, A2, A3, A4, A5, A6

\section{Having the right to speak}

The teacher's giving equal right to speak

A1, A2, A3, A4, A5, A6

Respecting thoughts and ideas

A1, A2, A3, A4, A5, A6

The democratic, just, and free classroom

A1, A3, A4

environment

The learning

environment in the

dialogic teaching of

a socio-scientific

issue

\section{The learning environment appreciated}

An environment where different ideas are

A1, A2, A3, A4, A5, A6

shared and discussed

No intervention in ideas

$\mathrm{A} 1, \mathrm{~A} 3, \mathrm{~A} 4, \mathrm{~A} 5$

Learning ideas by establishing connections

A3, A4, A5, A6

between them

There is no single correct answer

Making lessons enjoyable and interesting

A4, A5, A6

A1, A2, A3, A4, A5

The learning environment is not

appreciated

Everybody speaking at the same time

A1, A6

Intervention in ideas

A2, A6

Inadequate class time

A5

Making changes in the learning

environment

Learning in different, crowded classrooms

A2

Supporting the lesson with supplementary

materials

Student

Emotions evoked by the lesson in the

characteristics in the

student 
E, Uçak, A.S. Gencer, A. Seviş, \& S. Usta / Pamukkale University Journal of Education, 55, 294-323, 2022303

dialogic teaching of Positive emotions (curiosity, interest, like, A1, A2, A3, A4, A5, A6 a socio-scientific willingness)

issue

Both positive and negative emotions

A3, A4

Student-student

The effect of students on each other's

interaction in the ideas

dialogic teaching of

Ideas not differentiating

$\mathrm{A} 1, \mathrm{~A} 2, \mathrm{~A} 3$

a socio-scientific

Ideas differentiating

A4, A5, A6

issue

\section{Teacher-student roles in the dialogic teaching of a socio-scientific issue}

The participating students' opinions about the themes emerging concerning the roles of the teacher and students in the dialogic teaching of a socio-scientific issue are presented below.

Opinions about the roles of the teacher in the class. At the end of the lessons taught with dialogic teaching, the students were asked, "Do you liken your teacher's role to a mirror or a pole star in recent lessons?" All the students who participated in the interviews stated that they likened the role of their teacher in the last lessons to a pole star. One of these students (A4) expressed his/her opinions as follows:

In this lesson, I compared the role of our teacher to the one who guides us because everyone was allowed to express their opinions about GMOs clearly, and he just made his contributions. But if it were a normal science class, I would compare him to the one who reflects his knowledge because, in other science lessons, my teacher always talks about the subject and only helps us answer the questions. Then what he does is to reflect the information to us (Interview Transcript: A4).

We discussed the subjects we researched by putting forward different ideas, and the teacher was the one who offered guidance; that is, the right to speak. Therefore, I likened her to a pole star (A5):

I would liken her [the teacher] to a pole star because he provided guidance; as everybody did some research, everybody was putting forward different ideas, and thus, we were able to learn different ideas. Therefore, he was the one who provided guidance rather than the one who reflected information. We discussed the subjects we had researched by putting forward different ideas; therefore, I compared him to a pole star (Interview Transcript: A5). 
While teaching the lesson, he did not talk about his own ideas rather provided us with the necessary guidance (A1): "I compared my teacher to a pole star in this lesson because while teaching the lesson, he did not express his thoughts rather encouraged us to speak and provided us with the necessary guidance" (Interview Transcript: A1).

Opinions about the role of the student in the lesson. Except for student A2, the other students (A1, A3, A4, A5, A6) stated that they researched the subject and participated actively in the lesson. In addition, all the students stated that they freely expressed their opinions and defended their views. Student A1 stating that he/she defended his/her own ideas and participated in the lesson, expressed his/her opinions as follows:

I was active and interested because I defended my ideas and participated in the lesson. My participation in the lesson motivated me further. I also showed my attentiveness by defending my ideas because I loved and interested in the lesson (Interview Transcript: A1).

Pointing out that the students freely expressed their opinions and defended their own ideas, the student A4 explained his/her opinions as follows:

I enjoyed the discussions and conversations we had in this lesson because everyone was able to express their opinions openly and back up their views. They were able to defend their ideas. I liked the discussions and conversations about GMOs (Interview Transcript: A4).

The student A2 stating that their responsibilities in the lesson increased expressed his/her opinions as follows:

I think it is different because, in a normal lesson, our teacher reads the questions while conducting the lesson and gives the right to speak, etc. that is, the teacher directs the lesson. In this lesson, we talked more and had more turns to speak. Our teacher just asked questions in turn and got our ideas. In the discussion environment, we usually talked. Our teacher did not give his opinion. In this way, we took more responsibility. While we talked very little in a normal lesson, we already talked a lot in this lesson, plus we needed to manage the discussion environment in the lesson. In this way, we took more responsibility (Interview Transcript: A2).

\section{Classroom norms in the dialogic teaching of a socio-scientific issue}

The participating students expressed their opinions about timing and turned to speak about classroom norms. 
E, Uçak, A.S. Gencer, A. Seviş, \& S. Usta / Pamukkale University Journal of Education, 55, 294-323, 2022305

Opinions related to timing: The students (A1, A2, A3, A4, A5, A6) stated that they had sufficient time to think and talk about the question, and some students expressed their opinions as follows: "Yes, it was enough. Anyway, everyone was allowed to think about before the teacher gave time to talk, so our teacher gave enough time" (Interview Transcript: A1). "Yes, my teacher gave us enough time to express our ideas after asking questions. We even thought and reasoned a lot about the subject. He gave us a lot of time to express our views" (Interview Transcript: A4). "Enough time was given; I normally do not use so much time anyway, I give my answer shortly. So I think the time was enough. It was pretty good, and the time given was enough" (Interview Transcript: A2).

Opinions about turn to speak. In terms of turn to speak, the students (A1, A2, A3, A4, A5, A6) stated that the teacher gave equal right to speak to every student in the lesson taught through dialogic teaching on a socio-scientific issue, and some students expressed their opinions as follows:

Our teacher gave us the right to speak whenever we wanted. We were able to talk whenever we wanted. We talked in turn; not any student talked more than another. We talked in turn; everyone respected each other's opinions. The lesson was carried out in a just manner. It was good, so it was fun (Interview Transcript: A4).

We were given the right to speak in turn. In my opinion, this was better because everyone had to speak; otherwise, some students would have spoken, while some others would not have bothered to speak. They may have talked rarely. That is, giving the right to speak in turn was highly efficient. This was good for me; I have always wanted it to happen so (Interview Transcript: A2).

The students (A1, A2, A3, A4, A5, A6) stated that thoughts and ideas were respected, and some of them expressed their opinions as follows:

My friends respected my opinion because no one interrupted me while I was speaking. I also did not interrupt my friends while they were speaking. We respected each other. I was very happy as they respected my opinion. I was very happy, but I would have been very sad if my opinion had not been respected. I mean, if they had interrupted my speech and not let me speak, I would have been very upset. But they respected my opinion (Interview Transcript: A3).

I think my friends respected my opinion during the discussion because they were understanding and stated their opinions about what I talked about by stating they agreed or disagreed respectfully. They must have compared it with their ideas, as 
some said they agreed with me, and some said they didn't. If they hadn't respected me, they wouldn't have cared about me; they would have acted with their own ideas and thoughts without ever questioning my opinion (Interview Transcript: A5).

Some students (A1, A3, A4) stated that the lessons were carried out in a democratic, just, and free classroom environment and student A3 expressed his/her opinions as follows:

Yes, I was able to speak whenever I wanted. Everyone was able to speak equally without interrupting each other. Everyone in the class was able to speak anyway, because our teacher gave us the right to speak whenever we wanted. We didn't interrupt anyone (Interview Transcript: A3).

\section{The learning environment in the dialogic teaching of a socio-scientific issue}

The participating students expressed their likes and dislikes regarding the learning environment in the dialogic teaching of a socio-scientific issue and the features they wanted to change in the environment.

Opinions about the learning environment are appreciated. The features liked by the students in the learning environment where a socio-scientific issue was taught through dialogic teaching are that in the environment, different ideas were shared and discussed (A1, A2, A3, A4, A5, A6), that the sharing of the ideas was not interrupted (A1, A3, A4, A5), that the ideas were learned by establishing connections between them (A3, A4, A5, A6), that there was no single correct answer in the dialogic teaching of a socio-scientific issue (A4, A5, A6) and that the discussion of a socio-scientific issue made the lesson enjoyable and interesting (A1, A2, A3, A4, A5).

The student A3, who pointed out that it was a classroom environment where different ideas were shared and discussed, expressed his/her opinions as follows:

I really enjoyed the discussions we had about the lesson. The conversations we had, the questions we discussed with our friends on a topic and our discussions about them, I liked them all very much. Everyone was able to express their opinion clearly, which I liked very much (Interview Transcript: A3).

Student A4, who pointed out that no intervention was made in ideas, expressed his/her opinions as follows: "Our teacher and friends did not interrupt me. We conducted the lesson without interrupting each other. We continued our lesson without offending and upsetting each other. That is, nobody interrupted each other" (Interview Transcript: A4). 
E, Uçak, A.S. Gencer, A. Seviş, \& S. Usta / Pamukkale University Journal of Education, 55, 294-323, 2022307

The student A6, who pointed out that they learned the ideas by establishing connections between them, expressed his/her opinions as follows:

I myself researched, but there might be some information that I could not find, but my friends found. Or there might be some information I found, but my friends did not see. What I saw during my research might not have been seen by my friends and what they saw in their research might not have been seen by me; thus, we could complete each other. It was nice for others to continue adding something to what one of us had already said (Interview Transcript: A6).

The student A4, who pointed out that there was no single answer in the dialogic teaching of a socio-scientific issue, expressed his/her opinions as follows:

I think that the lessons focused on the subject of GMOs were different from the previous ones because everybody spoke in these lessons. Everybody expressed their own opinions. Everyone was allowed to defend their opinions. As there is no single answer to the issue of GMOs, everybody put forward their own opinions. Generally, there is only one correct answer to a question in a normal science lesson. Everyone is expected to say this correct answer. Therefore, I think these lessons differed from the previous ones (Interview Transcript: A4).

The students A1 and A4, who pointed out that it made the lesson enjoyable and interesting, expressed their opinions as follows:

Yes, I think it was different because we are taught the subjects in the units in normal science lessons, but here we were instructed on GMOs, a socio-scientific issue. Everybody focused on the same issue, and thus, the lesson was more enjoyable. Everybody defended their own ideas (Interview Transcript: A1).

It was good; the lesson was more exciting for us and thus we felt more enthusiastic. This was because of the way we were taught the lesson (Interview Transcript: A4).

Opinions about the learning environment are not appreciated. The features not liked by the students in the learning environment where a socio-scientific issue was taught through dialogic teaching are that everybody spoke at the same time, that what was said was not understood from time to time (A1, A6), that there occurred some interventions in ideas (A2, A6) and that the lesson time was not enough (A5).

The students A1 and A6, who pointed out that everybody spoke at the same time and thus what was said was not understood from time to time, expressed their opinions as follows: "While we were discussing, we all talked at the same time, and the answers given 
by some students were not understood; therefore, it did not like it (Interview Transcript: A1). "For example, sometimes everyone wanted the right to speak. While one person was talking, the other interrupted to say his/her opinions. I didn't like it" (Interview Transcript: A6).

From among the students pointing to the interventions made in ideas, student A2 expressed his/her opinions as follows: "There were some students continuously interrupting us. There were some students interrupting us; apart from this, the lesson was delightful" (Interview Transcript: A2).

From among the students pointing out that the lesson time was inadequate, student A5 expressed his/her opinions as follows: “Honestly, there wasn't a feature I didn't like very much. It was very nice. What I didn't like ... It was just a bit short; it would be better if it took much longer than 6 lessons" (Interview Transcript: A5).

Opinions about making changes in the learning environment. To the question "What would you change in the learning environment where a socio-scientific issue was taught with dialogic teaching, if you were allowed to do so?", student A2 stated that he/she would like to learn the subject in different, crowded classrooms and the student A1 stated that the lesson should be supported with supplementary materials.

The student A2, who pointed out that he/she would like to learn the subject in different, crowded classrooms, expressed his/her opinions as follows:

Maybe it would be better if it was done with two classes instead of a single class, in a more crowded environment because we know each other and thus, we can guess who will say what but since we don't know anyone from another class, it would be different, it could be better (Interview Transcript: A2).

Student A1, who pointed out that the lesson should be supported with supplementary materials, expressed his/her opinions as follows:

If I were allowed to make a change, I would like models to be made related to GMOs. In other words, a tomato model can be made by putting pepper in it, that is, by putting the inside of the pepper. I would like to make a model that can combine two fruits (Interview Transcript: A1).

\section{Student Characteristics in the Dialogic Teaching of a Socio-Scientific Issue}

All the participating students (A1, A2, A3, A4, A5, A6) stated that they had positive emotions about the lesson taught with dialogic teaching on a socio-scientific issue, while 
E, Uçak, A.S. Gencer, A. Seviş, \& S. Usta / Pamukkale University Journal of Education, 55, 294-323, 2022309 some students (A3, A4) stated that they felt sorry when their friends did not agree with them.

The student A5, who pointed out that he/she felt willing, curious, and exciting, expressed his/her opinions as follows:

I felt excited at first. It was the first time I attended such a class, I wondered what would happen, and then I relaxed. Then, I became curious and willing; I became active, I think I was active. I was happy in the class (Interview Transcript: A5).

From among the students (A3, A4) stating that they felt sorry when their friends did not agree with him/her, student A4 expressed his/her opinions as follows:

I felt happy when my friends agreed with me. I felt very happy. But sometimes, some of my friends did not agree with my opinion, although this issue of GMOs is a very open subject, which made me sad. I felt as if I was wrong. I felt that I should defend myself. I defended myself (Interview Transcript: A4).

\section{Student-student interaction in the dialogic teaching of a socio-scientific issue}

The students' opinions about student-student interaction in the lesson taught by means of dialogic teaching are given below.

Opinions about ideas' not differentiating. From among the students indicating that their ideas did not change by stating that their ideas were correct and they defended their ideas, student A2 expressed his/her opinions as follows:

That is, when I heard the opinions of my friends, my opinion did not change because I thought my ideas were correct. Did anything change in the discussion environment afterwards? We made some small changes in some places, but I did not change my opinion completely; I defended my opinion. That is, while I was telling that something was correct, others were told that it was wrong. That is, in my opinion, we should not change our mind because, of course, if what they say is correct, we can change our mind, but I defended my opinion because I thought that I was right (Interview Transcript: A2).

Opinions about ideas' differentiating. From among the students stating that some of their ideas changed when they heard the opinions of my friends, student A5 expressed their opinions as follows:

When I heard the opinions of my other friends, some of my opinions changed because when they said it, I took a look at it. I thought about what my friends said. 
Sometimes I agreed with him/her when my opinion was wrong, and sometimes I defended my opinion when I saw that his/her opinion was wrong (Interview Transcript: A5).

\section{Findings from the Drawings of the Students}

Below are the pictures drawn by the students participating in the study and their explanations based on the drawings.

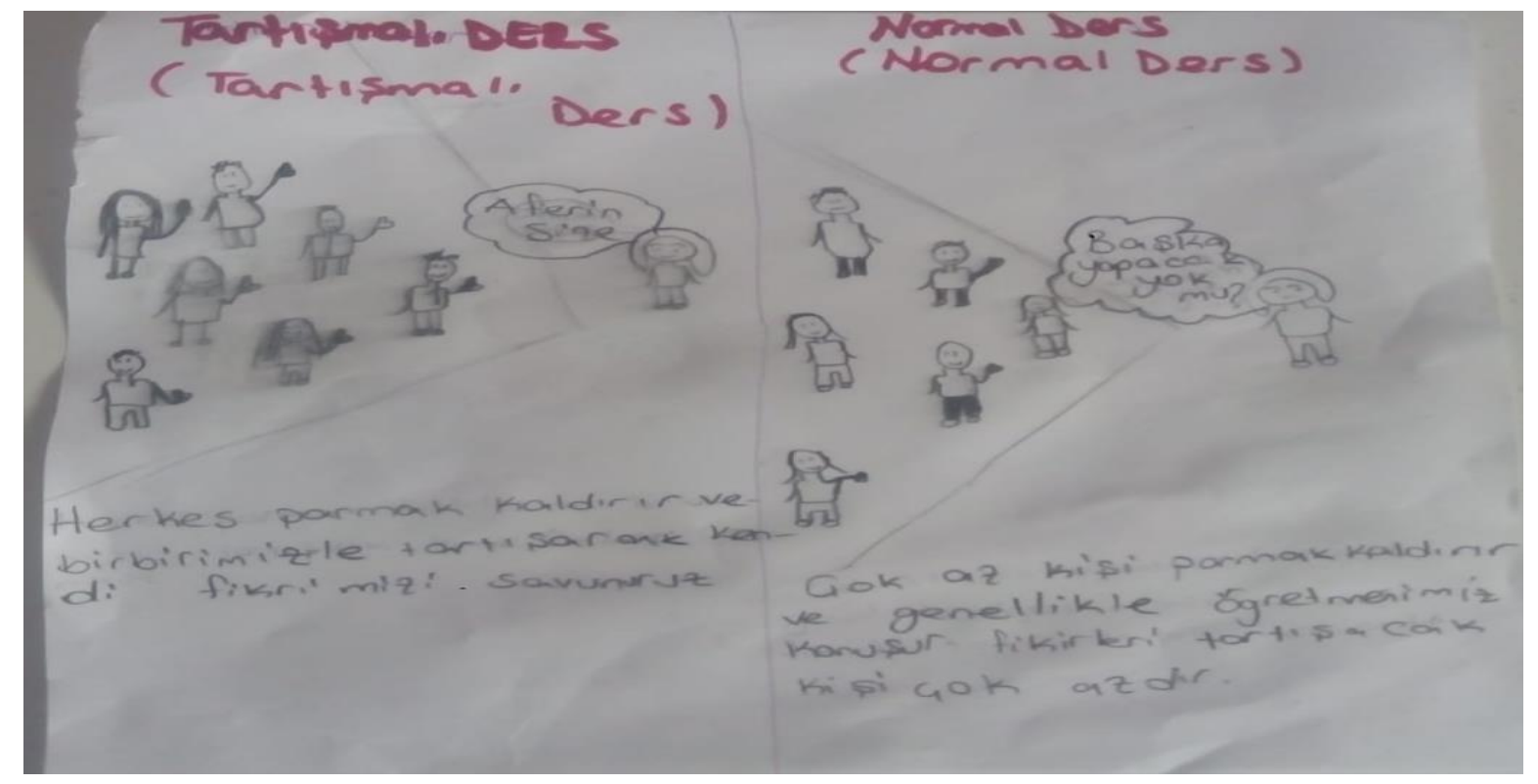

Figure 1. The drawing of student Al comparing the lessons taught with dialogic teaching and the previously taught lessons

In the drawing produced by student A1 given in Figure 1, he/she called the previous lessons (on the right) normal lessons and stated, "Very few people raise their hands, and usually our teacher speaks. The number of people speaking is very few." In the drawing of the lesson (on the left) taught with dialogic teaching on the subject of GMOs, all students raise their hands. He/she drew attention to the active participation of the students in the lesson and made the following explanation for the picture, "Everyone raises their hands, and we argue with each other and defend our own ideas." 


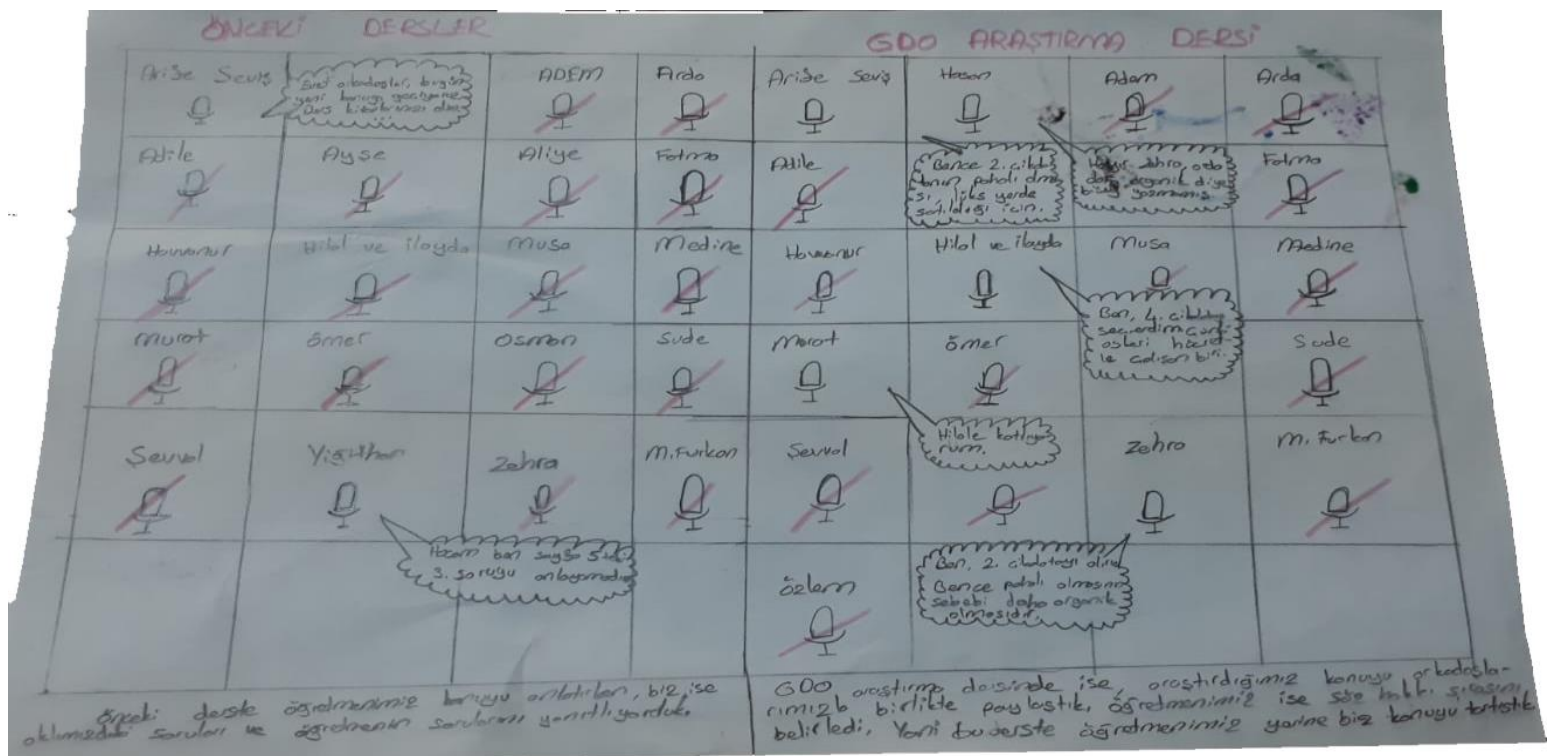

Figure 2. The drawing of the student A2 comparing the lessons taught with dialogic teaching and the previously taught lessons

In the drawing produced by student A2 in Figure 2, he/she clearly drew his teacher's microphone and one of his/her friends in the previous lessons (on the left). All the other students have their microphones turned off in class. The teacher said, "Friends, we are going to proceed to a new topic today, open your books!" while the student with the microphone on said, "I don't understand the $3^{\text {rd }}$ question on page 5." This is the only teacher-student interaction. He/she also explained, "In the previous lessons, the teacher was explaining the subject, and we were answering the questions in our minds and asked by the teacher."

In the drawing and explanation of the lesson (on the right) on GMOs, the microphones of the teacher and five students were drawn turned on. While one of the speaking students stated, "I would choose the $4^{\text {th }}$ chocolate because he/she is a minimum wage worker." the other said, "I agree with Hilal," and another said, "I would choose the $2^{\text {nd }}$ chocolate because it is expensive as it is organic." Therefore, he/she noted that more students were talking in the lesson and that the students' opinions also differentiated. In his/her explanation, he/she wrote, "We shared the subject we researched in our lesson on GMOs with our friends, and our teacher determined our order of the right to speak. That is, in this lesson, we spoke rather than our teacher." 

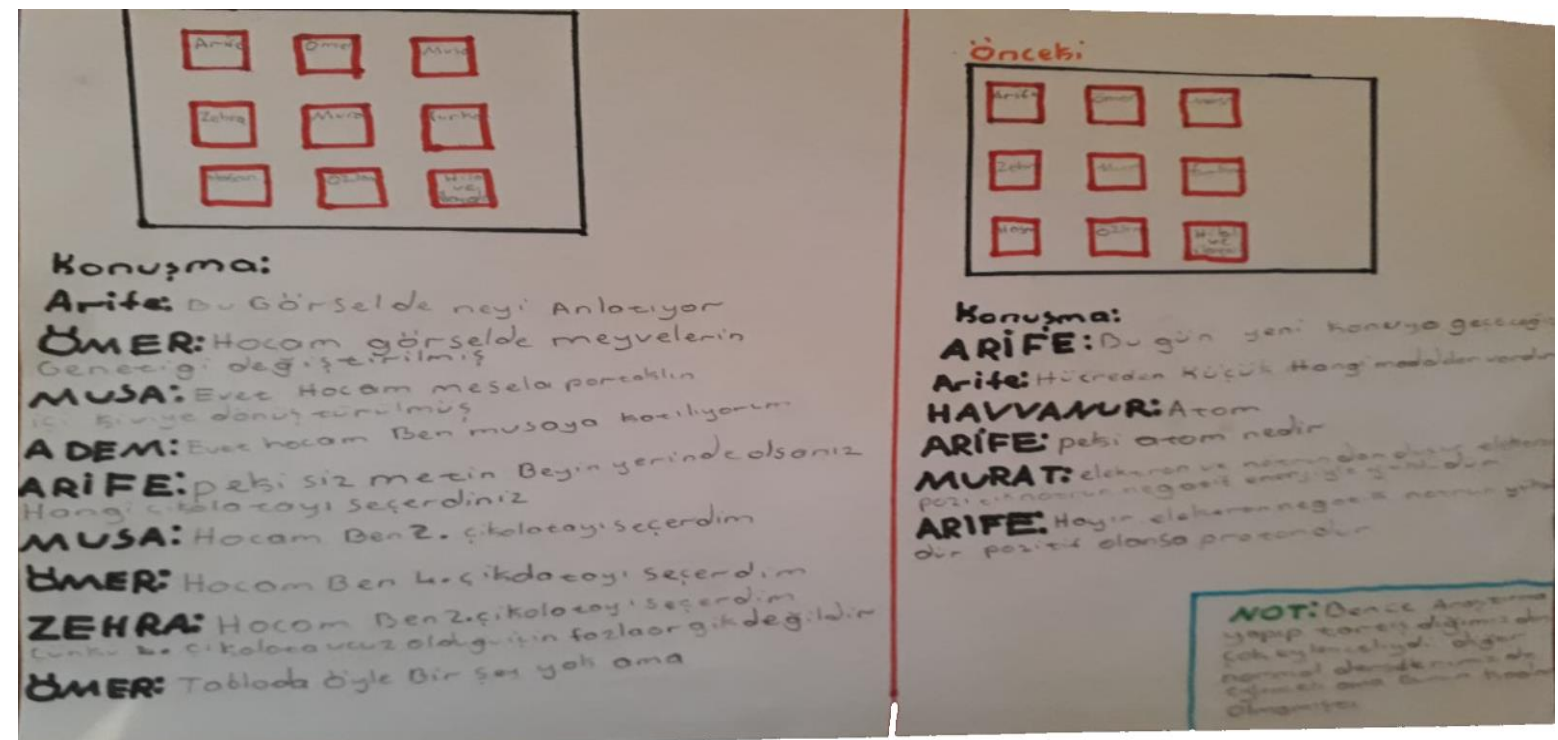

Figure 3. The drawing of the student A3 comparing the lessons taught with dialogic teaching and the previously taught lessons

In the drawing by A3 given in Figure 3, he/she illustrated the brief interaction between two students responding to the teacher's closed-ended question in the previous lessons (on the right). The interaction pattern he/she illustrated is the authoritative interactive communicative approach, commonly used in science classes and refers to traditional teaching, defined as IR (Initiation-response) and IRE (Initiation-responseevaluation).

In his/her drawing and explanation of the lesson (on the left) taught with dialogic teaching, the views received from different students about the scenario given by the teacher are illustrated. In the note he/she wrote, the student made the following explanation; "I think this lesson in which we researched and discussed is more fun than our other normal lessons." From the explanations below in the drawing produced by student A3, it is understood that dialogic teaching changes the teacher-student interaction and makes the lesson more fun. 


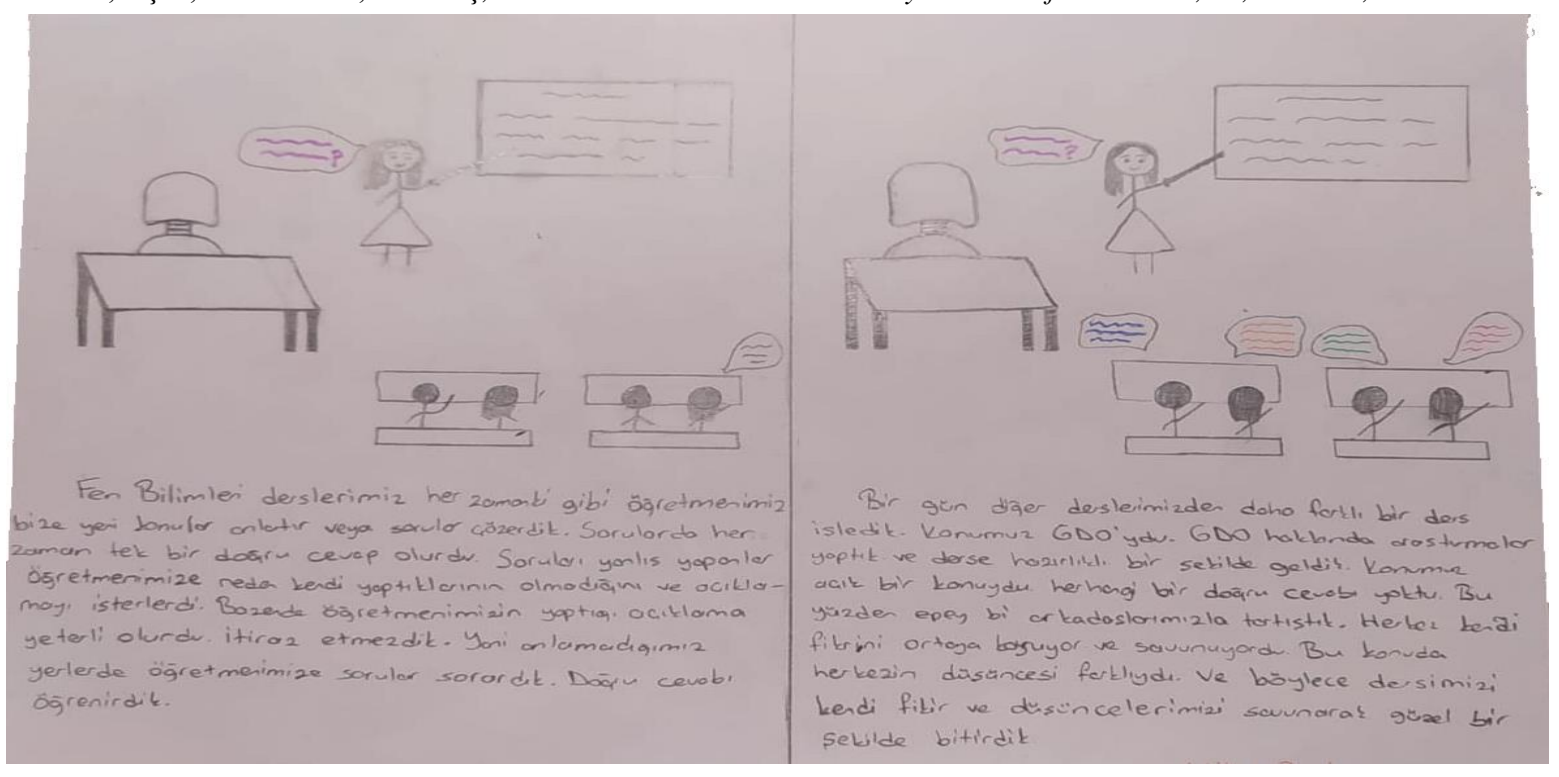

Figure 4. The drawing of the student A4 comparing the lessons taught with dialogic teaching and the previously taught lessons

In the drawing produced by the student A4 given in Figure 4, it is shown with speech bubbles that a single student spoke in the previous lessons (on the left) and four students spoke in the lesson (on the right) taught with dialogic teaching on the subject of GMOs. In the explanation of the drawing on the left, which he/she drew to depict a normal lesson, he/she wrote as follows:

As usual, our teacher teaches us topics or we solve questions. There is a single answer to each question. The students giving wrong answers to the questions ask their teacher to explain why their answers are wrong. The explanation made by our teacher is found to be sufficient and we do not object to it. That is, we ask questions when we do not understand something. Thus, we learn the correct answer (Written explanation: A4).

The drawing on the right produced to illustrate the lesson taught with dialogic teaching on the subject of GMOs he/she wrote the following explanation:

It was different from our previous lessons. Our subject was GMOs. We conducted research on GMOs and we got ready for the lesson. The subject was an open subject and there was no single correct answer. So we had a lot of discussion with our friends. Everyone was expressing and defending his/her own opinion. Everyone's opinion on this matter was different, so we ended our lesson by defending our own ideas and thoughts (Written explanation: A4). 


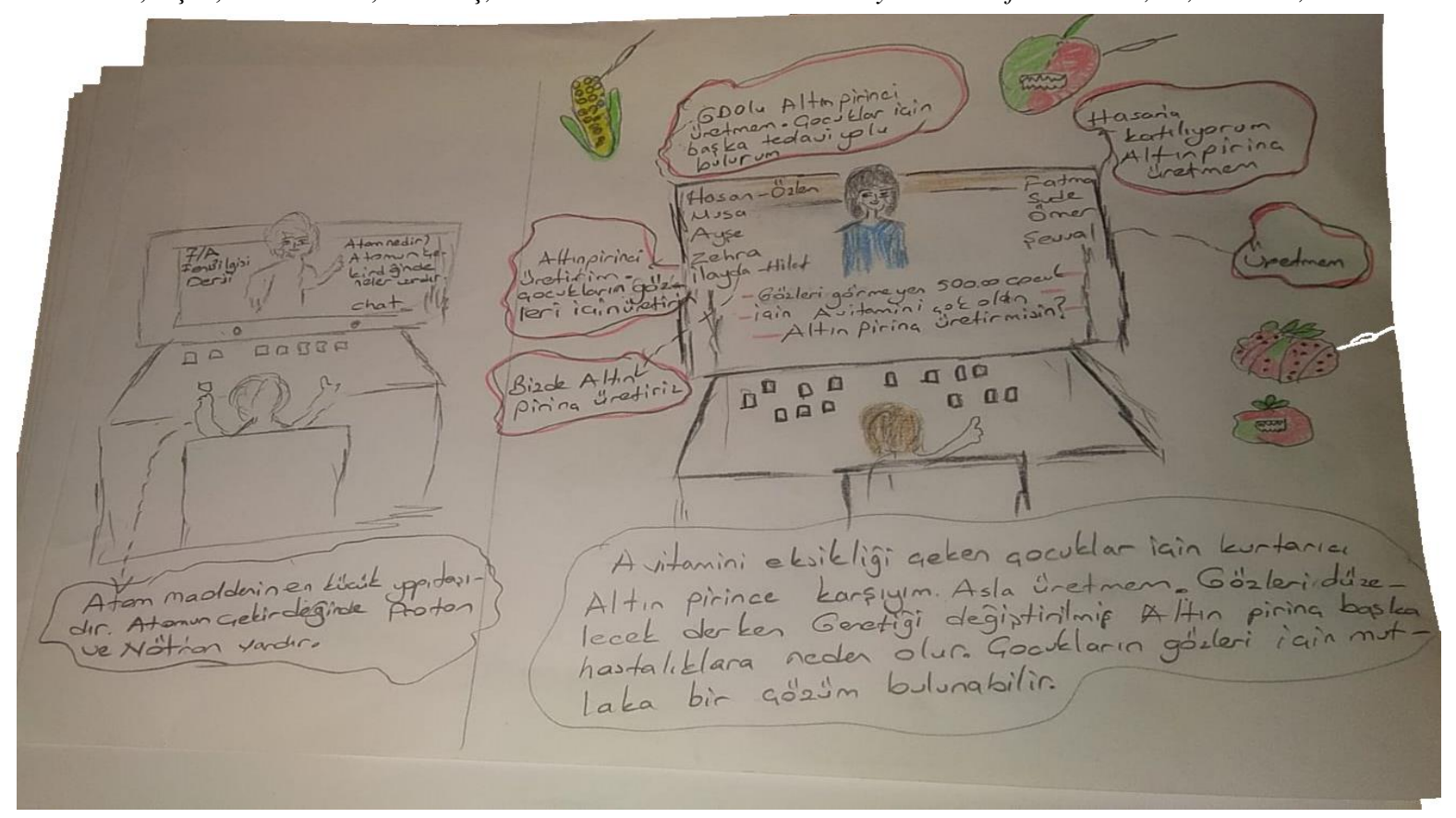

Figure 5. The drawing of the student A5 comparing the lessons taught with dialogic teaching and the previously taught lessons

In the drawing produced by the student A5 in Figure 5, in the illustration of the previously taught lessons (on the left), the teacher asked, "What is an atom? What is in the nucleus of the atom?" And a student answers the question, "The atom is the smallest building block of matter. There are protons and neutrons in the nucleus of the atom."

In the lesson taught with dialogic teaching on the subject of GMOs (on the right), the names of most of the students in the class are written next to the teacher. The teacher asks the question, "Can you produce golden rice for 500,000 blind children?" And the student' opinions are explained within speech bubbles. He/she wrote the following explanation under the picture:

I am against the golden rice serving as a rescuer for children with vitamin A deficiency. I never produce it. While trying to cure the problem in their eyes, some other problems can be caused with the use of genetically modified golden rice. Some other solutions can be found to the problem in the eyes of these children (Written explanation: A5). 


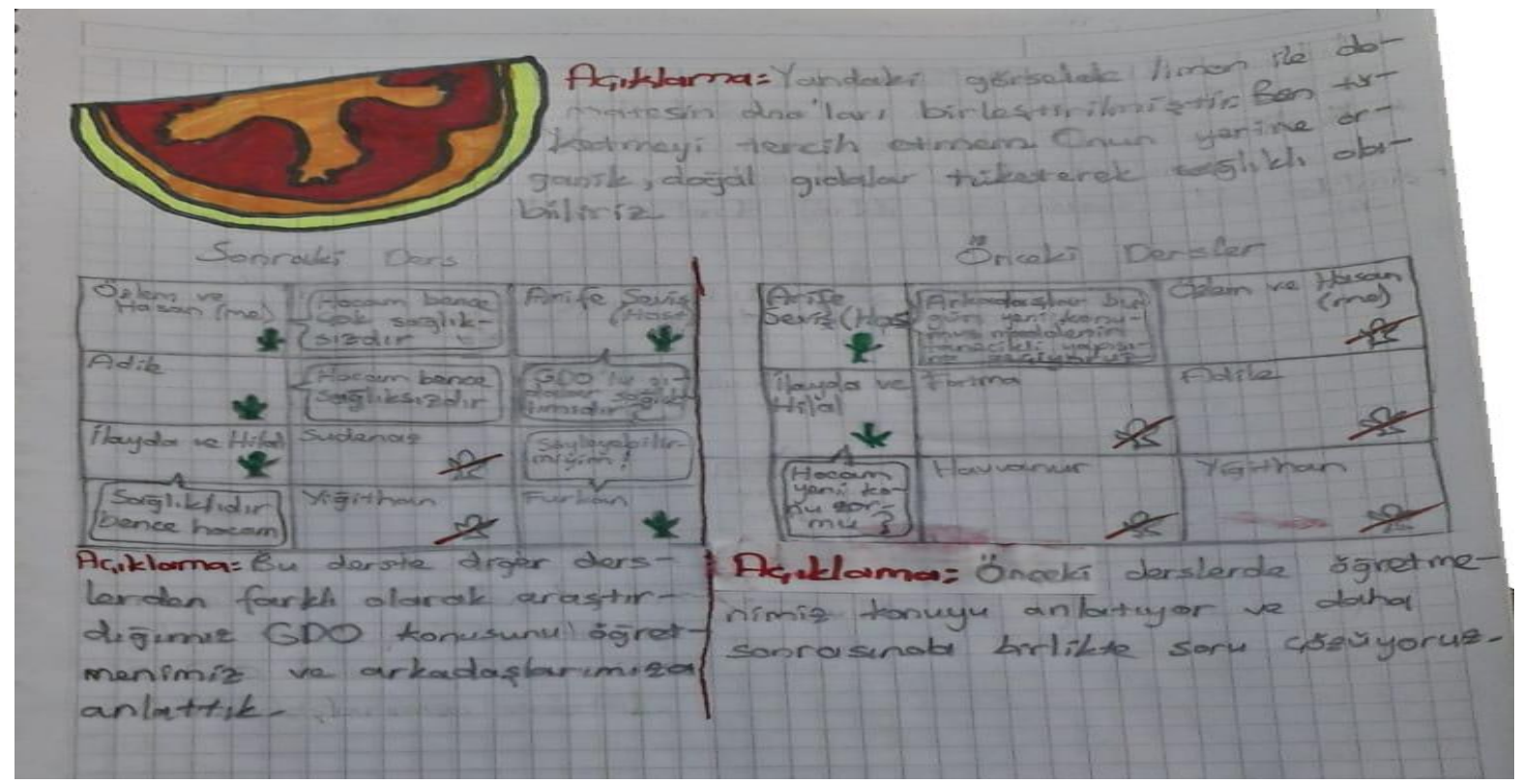

Figure 6. The drawing of the student A6 comparing the lessons taught with dialogic teaching and the previously taught lessons

In the drawing of the student A6 given in Figure 6 regarding the previously taught lessons (on the right), only the microphone of the teacher and that of one of the students are on. The microphones of all the other students are off. In the drawing, while the teacher is explaining the subject they will address in the lesson, the student with his/her microphone on asks the question, "Teacher, is the subject difficult?" This is the only teacher-student interaction. The student A6 made the following explanation for this drawing, "In the previous lessons, the teacher teaches the subject and then we together solve the questions."

In the drawing (on the left) depicting the lesson taught with dialogic teaching on the subject of GMOs, only two students' microphones are off, while the microphones of all the other students in the class are on. While the majority of the speaking students used the word "unhealthy" for GMOs, one student used the word "healthy". Therefore, he/she drew attention to the fact that more students are talking in the class. He/she made the following explanation for his/her drawing, "Different from the previous lessons, not the teacher but the students talk about the subject of GMOs on the basis of the research they have done."

\section{Results, Discussion and Suggestions}

In the current study, the students' opinions about the dialogic teaching environment created for the teaching of the subject of GMOs, a socio-scientific issue, were taken and the students were asked to explain their visual modelling of the previously taught science lessons and the lessons taught with dialogic teaching by means of drawing. Dialogical teaching practices, in 
which student contributions are valued, are important in terms of expressing students' perspectives on socio-scientific issues and providing students with opportunities to see and think about the perspectives of others (Ratcliffe and Grace 2003; Zeidler, Sadler, Applebaum and Callahan, 2009). The use of dialogical classroom practices that take students' perspectives into account and engage them in an interactive way imposes new responsibilities on science teachers because most science teachers do not have the teaching strategies necessary to manage discussions (Bryce and Gray 2004). In this connection, a science teacher, who was seen to use very authoritative discourses in his lessons before the study, was given training on dialogic teaching for 12 weeks. The existing research indicates that the teacher's consideration of students' contributions promotes student engagement and interest in classroom discourse (Nystrand 1997; Smith and Higgins, 2006). Importance attached to students' contributions can be demonstrated by the teacher allowing student contributions to give direction to interactions or student ideas to guide subsequent discussions, or considering new perspectives put forward by a student in greater detail (Nystrand 1997). Thus, students are positioned as legitimate participants in classroom discourse. When the interview findings of the current study were examined, it was seen that all the students who participated in the study compared their teacher to a pole star; that is, a guide and that they positioned themselves as participants who actively participated in the lesson, who freely spoke and defended their ideas and researched.

Again, in the drawings produced by the students, it was seen that the students positioned themselves as more active and more involved in the lessons taught with dialogic teaching on the subject of GMOs, a socio-scientific issue. According to Han Tosunoğlu and İrez (2019), “a teacher who will teach a socio-scientific issue should adopt a dialogue-based teaching approach, have content knowledge on socio-scientific issues and exhibit a studentcentred approach rather than a teacher-centred approach in the classroom" (p.395), accordingly "he/she must position himself/herself as a person contributing to the discussion rather than a figure of authority" (p.393). In this context, the teacher-student positioning emerging from the student interviews indicates a student-centred approach. The fact that all the students participating in the study could reflect their own choices in the explanations of their drawings related to the lessons taught with dialogic teaching, instead of the expressions dictated to them by the authority, shows that a learning environment was formed in which they were able to take part in the classroom discourses. According to Karahan (2021), who draws attention to the fact that the diversity of voices in classroom discussions can be 
E, Uçak, A.S. Gencer, A. Seviş, \& S. Usta / Pamukkale University Journal of Education, 55, 294-323, 2022317 achieved with student autonomy, "the clarification of the concept of agency in classroom discourse has a remarkable importance in reaching the goal of science literacy in particular literacy of socio-scientific issues" (p. 45).

All the students who participated in the study stated that in terms of classroom norms in dialogic teaching, they were given enough time by their teacher to think about the questions and that they were given enough talking time about the questions. In teacherstudent interactions, teachers should allow sufficient waiting time for student responses. Giving enough waiting time allows students to think longer and to make more reasoned sentences, to increase the variety in answers and to turn to the analysis and synthesis step (Ingram and Elliott, 2014). Again, all the students stated that the teacher gave them equal rights to talk and respected their thoughts and ideas. Some students pointed out that a democratic, fair and free classroom environment was provided for them. Han Tosunoğlu and İrez (2019) stated that "it is important to create a collaborative, democratic learning environment where individuals respect each other's ideas for the teaching of socio-scientific issues" (p.399). While all the interviewed students drew attention to the creation of an environment where different ideas were shared and discussed, some students emphasized that they were not interrupted while expressing their ideas, that they were encouraged to learn by discussing with their friends and that a single scientific answer was not sought for questions in the lesson.

While all the students, who participated in the interview, stated that the lesson taught with dialogic teaching was fun and interesting and that teaching the lesson in this way created curiosity, interest and desire in them. According to the findings of Smit, Brabander, and Matens (2014), if students have an effective role in learning environments, they make more effort in the name of learning and are involved in the learning process with a higher sense of pleasure. Again, in the study carried out by Cornelius-White (2007), it was revealed that the approaches in which students are at the centre of learning increase student participation, motivation, self-esteem and social interaction. On the other hand, two students stated that they felt upset when their friends did not agree with their opinions, which created negative emotions in them. This might be because of the fact that the students encountered such a situation for the first time and that it was not a situation they were accustomed to.

Some students who participated in the interview expressed that they did not like some elements in the dialogic learning environment. These students pointed out that from time to time all the students in the class spoke at the same time and thus some of the ideas 
were not understood, that they were sometimes interrupted by their peers and that the lesson time was not enough. In classrooms, where dialogic teaching is carried out, it may take time for the speaking rules to settle. Cobb, Gravemeijer, Yackel, McClain, and Whitenack (1997) focused on the concept of classroom norms in order to strive to establish norms for the inculcation of the skills valued by contemporary teaching approaches, and to abandon norms that contradict this. Özmantar, Bingölbali, Demir, Sağlam, and Keser (2009) summarized the classroom norms as follows: explaining the thoughts, presenting the reasons for the thoughts, all students' sharing their ideas without hesitation, students' trying to understand all the thoughts shared in the class, all students' stating whether they participated in the activities, producing different explanations and questioning the accuracy of the explanations.

While half of the students who participated in the interviews stated that their peers' views on the subject did not affect their opinions within the context of student-student interaction in the dialogic learning environment, that is, they defended their own arguments, the other half stated that they changed their minds when they heard their friends' arguments. When the drawings and explanations of these students were examined, it was seen that the teacher had not given enough opportunity to interact with their peers by using authoritative approaches in the previous science lessons. The findings concur with the characteristics of traditional teachers revealed in the classification made by Tsai (2002). In this classification, traditional teachers' views and practices in science teaching were evaluated as follows: Science is best learned through the transfer of knowledge from teacher to student. Behaviours that confirm this point of view are: information transfer; giving the first answer; making clear definitions; giving precise, accurate explanations, presenting scientific facts or phenomena. In the literature, Akış (2012) compared the classroom environments where authoritative and dialogic discourses emerged to reveal the differences between them. According to the authoritative teacher, the teacher is the source of knowledge, and the student is the person who tries to find the truth and approves the teacher. According to the dialogic teacher, the teacher is the one who cares about the different ideas of students, listens to them, does not judge but encourages them to produce new ideas; on the other hand, a student is a person who produces ideas, cares about the ideas of others, listens and discusses. Again, all the drawings reveal authoritative and dialogic learning environments very clearly in this respect. In addition, when the questions depicted to be posed by the teachers during science teaching in some drawings (Figure 3 and Figure 5) are examined, it is seen that they are generally lower-order cognitive questions. On the other hand, according to Yilmaz 
E, Uçak, A.S. Gencer, A. Seviş, \& S. Usta / Pamukkale University Journal of Education, 55, 294-323, 2022319 (2017), while productive teacher talks lead the student to reasoning, questions that are not deep lead to short-answer, true-false answers, thus limiting the student's response options or leading him/her to giving no answer.

Studies investigating classroom discourses gain importance in science education. In the study conducted by Yıldırım, Uçar, and Savran Gencer (2021), it was revealed that publications based on classroom conversations were published more especially in Web of Science than other field indexed journals, and the number of studies in this field was increasing day by day. Within the studies focused on classroom conversations, the number of publications based on dialogic teaching is increasing. However, in our country, studies on dialogic teaching are very limited when Ulakbim and thesis studies are examined.

When the study is evaluated in terms of teaching socio-scientific issues, the teaching environment should be dialogic and reflective due to the nature of socio-scientific issues (Lee et al., 2012). Saunder and Rennie (2013) also emphasize that the teaching of socioscientific issues cannot be possible with a didactic and teacher-centred approach and the function of questioning in the teaching process of socio-scientific issues is to provide awareness of different perspectives rather than making a decision. Again, in the model proposed by Sadler (2011) for the teaching of socio-scientific issues, it is emphasized that the classroom environment is important and that students and teachers should feel safe and in a democratic classroom environment. Therefore, teachers are expected to create a democratic and open-minded classroom environment where everyone can express their opinions freely. In classrooms where socio-scientific issues are addressed, students should be encouraged to participate in various forms of discourse that allow their learning to progress through collaboration and reciprocal shaping of epistemological understandings.

Findings from the studies of Kanatlı (2012) and Uçak (2014) also showed that when teachers and pre-service teachers were trained efficiently, they were able to integrate dialogic discourses into their classrooms at the end of the training. In this regard, it is suggested that training should be given to teachers and pre-service teachers in order to raise their awareness of dialogic teaching. Research that reflects teacher experiences related to dialogic teaching can be done. In addition, the current study is the first study to reveal the perspective of students about the lessons taught with dialogic teaching. Therefore, more studies can be conducted and classroom practices can be evaluated from the student's point of view. In the study conducted by Hajhosseiny (2012), it was determined that the students in the group in which the Socratic dialogue was applied improved in their critical thinking 
and social communication skills (e.g., recognition of each other, friendship and sincerity, tendency to communicate, responsibility, classroom dynamism, communication with the teacher, sincerity with the teacher). It is thought that dialogic teaching in classrooms is important for the development of such higher-order skills. Therefore, all these factors can be examined in different studies.

Ethical Approval: This study was carried out with the approval of Pamukkale University Social and Human Sciences Scientific Research and Publication Ethics Committee with the decision dated 25/02/2021 and numbered 68282350/2018/G04.

Conflict Interest: There is no conflict of interest between the authors of this article.

Authors Contributions: In all the stage of the study, the authors made equal contributions.

\section{References}

Akış, A. (2012). Otoriter ve diyalojik öğretmenlerin ögretmen-öğrenci rollerine dair beklenti ve inançlart. Unpublished master thesis. Gaziantep University, Gaziantep.

Aleaxander, R. (2006). Towards dialogic teaching: Rethinking classroom talk. Cambridge: Dialogos.

Almahrouqi, A. \& Scott, P. (2012). Classroom discourse and science learning. In D. Jorde \& J. Dillon (Eds.), Science education research \& practice in Europe: Retrospective and prospective (pp. 291-307). Rotterdam, Netherlands: Sense publishers.

Billings, L. \& Fitzgerald, J. (2002). Dialogic discussion and the Paideia Seminar. American Educational Research Journal, 39(4), 907-941. https://doi.org/10.3102/00028312039004905

Bryce, T. \& Gray, D. (2004). Tough acts to follow: The challenges to science teachers presented by biotechnological progress. International Journal of Science Education, 26(6), 717-733. https://doi. org/10.1080/0950069032000138833

Chin, C. (2006). Classroom interaction in science: Teacher questioning and feedback to students' responses. International Journal of Science Education, 28 (11), 1315-1346.

Cobb, P., Gravemeijer, K.P.E., Yackel, E., McClain, K., \& Whitenack, J.W. (1997). Mathematizing and symbolizing: The emergence of chains of signification in one 
E, Uçak, A.S. Gencer, A. Seviş, \& S. Usta / Pamukkale University Journal of Education, 55, 294-323, 2022321

firstgrade classroom. In: D. Kirschner \& J. Whitson (Eds.), Situated cognition theory: Social, semiotic, and neurological perspectives (pp. 151-233). Mahwah, NJ: Lawrence Erlbaum Associates.

Corden, R. (2009). Literacy and learning through talk. Open University Press.

Cornelius-White, J. (2007). Learner-centered teacher-students relationships are effective: A meta-analysis. Review of Educational Research, 77, 113-143. https://doi.org/10.3102/003465430298563.

Çepni, S., (2007). Araştırma ve proje çalışmalarına giriş. Trabzon: Celepler Matbaacılık.

Game, A. \& Metcalfe, A. (2009). Dialogue and team teaching. Higher Education Research \& Development, 28(1), 45-57.

Hajhosseiny, M. (2012). The effect of dialogic teaching on students' critical thinking disposition. Procedia-Social and Behavioral Sciences, 69, 1358 - 1368.

Han Tosunoğlu, Ç. \& İrez, S. (2019). Sosyobilimsel konuların öğretimi için pedagojik bir model. Yüksekögretim ve Bilim Dergisi/Journal of Higher Education and Science, 9(3), 384-401. https://doi.org/10.5961/jhes.2019.340.

Hofstein, A., Eilks, I., \& Bybee, R. (2011). Societal issues and their importance for contemporary science education - a pedagogical justification and the state-of-the-art in Israel, Germany, and the USA. International Journal of Science and Mathematics Education, 9(6), 1459-1483. https://doi.org/10.1007 /s10763-010-9273-9.

Ingram, J. \& Elliott, V. (2014). Turn taking and 'wait time' in classroom interactions. Journal of Pragmatics, 62, 1-12. DOI: 10.1016/j.pragma.2013.12.002

Kanadlı, S. (2012). Öğretmenlere yönelik hazırlanan bir mesleki gelişim programının etkililiğinin incelenmesi. Unpublished doctoral dissertation, Gaziantep University, Gaziantep.

Karahan, E. (2021). Sosyobilimsel konularda öğrenci failliği. A. Yenilmez Türkoğlu ve D. Karışan, D. (Ed.), Sosyobilimsel Konular içinde (1.baskı s. 31-48). Ankara: Eğiten Kitap Yayıncılık.

Kılınç, A., Demiral, U., \& Kartal, T. (2017). Resistance to dialogic discourse in SSI teaching: The effects of an argumentation-based workshop, teaching practicum, and 
E, Uçak, A.S. Gencer, A. Seviş, \& S. Usta / Pamukkale University Journal of Education, 55, 294-323, 2022 induction on a preservice science teacher. Journal of Research in Science Teaching, 54(6), 764-789. https://doi.org/10.1002/tea.21385.

Kutnick, P. \& Colwell, J. (2010). Dialogue enhancement in classrooms. Towards a relations approach for group working. K. Littleton, C. Howe (Eds.), Educational dialogues: Understanding and promoting productive interaction (pp. 192-215). London: Routledge.

Lee, H., Yoo, J., Choi, K., Kim, S.-W., Krajic, J., Herman, B. C., \& Zeidler, D. L. (2013). Socio-scientific issues as a vehicle for promoting character and values for global citizens. International Journal of Science Education, 35(12), 2079-2113.

Levinson, R. (2004). Teaching bioethics in science: Crossing a bridge too far? Canadian Journal of Science. Mathematics and Technology Education, 4(3), 353-369. https://doi.org/10.1080/14926150409556619

Levinson, R., Douglas, A., Evans, J. E., Kirton, A., Koulouris, P., Turner, S., \& Finegold, P. (2001). Valuable lessons: engaging with the social context of science in schools [report]. Wellcome Trust, London.

Lyons, T. (2006). Different countries, same science classes: Students' experiences of school science in their own words. International Journal of Science Education, 28(6), 591613. https://doi.org/10.1080/09500690500339621.

Mercer, N. \& Littleton, K. (2007). Dialogue and the development of children's thinking: A sociocultural approach. UK: Routledge, London.

Miles, M. B. \& Huberman, A.M. (1994). Qualitative data analysis (2nd ed.). CA: Sage, Thousand Oak.

Mortimer, E.F. \& Scott, P.H. (2003). Meaning making in secondary science classrooms. Open University Press, Maidenhead/Philadelphia.

Nystrand, M. (1997). Opening dialogue: Understanding the dynamics of language and learning in the English classroom. New York, NY: Teachers College Press.

Nystrand, M., Gamoran, A., Kachur, R., \& Prendergast, C. (1997). Opening dialogue. Understanding the Dynamics of language and learning in the English classroom. New York, London: Teachers College Press. 
E, Uçak, A.S. Gencer, A. Seviş, \& S. Usta / Pamukkale University Journal of Education, 55, 294-323, 2022323

Nystrand, M., Wu, L.L., Gamoran, A., Zeiser, S., \& Long, D.A. (2003). Questions in time: Investigating in the structure and dynamics of unfolding classroom discourse. Discourse Processes, 35(2), 135-198.

Osborne, J., Duschl, R., \& Fairbrother, R. (2002). Breaking the mould? Teaching science for public understanding. London, UK: Nuffield Foundation.

Özmantar, M.F., Bingölbali, E., Demir, S., Sağlam, Y. ve Keser, Z. (2009). Değişen öğretim programları ve sınıf içi normlar. Uluslararası İnsan Bilimleri Dergisi, 6(2). http://www.insanbilimleri.com

Ratcliffe, M. \& Grace, M. (2003). Science education for citizenship: Teaching socioscientific issues. Maidenhead, UK: Open University Press.

Ratcliffe, M. \& Millar, R. (2009). Teaching for understanding of science in context: Evidence from the pilot trials of the "twenty first century science" courses. Journal of Research in Science Teaching, 46(8), 945-959. https://doi.org/10.1002/tea.20340.

Resnick, L. B., Asterhan, C. S. C., \& Clarke, S. N. (Eds.) (2015). Socializing intelligence through academic talk and dialogue. Washington, DC: American Educational Research Association.

Reznitskaya, A. \& Gregory, M. (2013). Student thought and classroom language: Examining the mechanisms of change in dialogic teaching. Educational Pschologist, 48 (2), 114-133. https://doi.org/10.1080/00461520.2013.775898

Sadler, T. D. (2011). Socio-scientific issues-based education: What we know about science education in the context of SSI. In T. D. Sadler (Ed.), Socio-scientific issues in the classroom: Teaching, learning and research (pp. 355-369). Dordrecht, The Netherlands: Springer. https://doi.org/10.1007/978-94-007-1159-4_20.

Saunders, K.J. \& Rennie, L.J. (2013). A pedagogical model for ethical inquiry into socioscientific issues in science. Research in Science Education, 43(1), 253-274. DOI 10.1007/s11165-011-9248-z.

Scott. P.H, Mortimer, E.F., \& Aguiar. O.G. (2006). The tension between authoritative and dialogic discourse: A fundamental characteristic of meaning making interactions in high school science lessons. Science Education, 90, 605-631. 
Scott, P., \& Ametller, J. (2007). Teaching science in a meaningful way: Striking a balance between 'opening up' and 'closing down' classroom talk. School Science Review, 88 (324), 77-83.

Scott, P., Ametller, J., Mortimer, E., \& Emberton, J. (2010). Teaching and learning disciplinary knowledge. In K. Littleton, \& Ch Howe (Eds.). Educational dialogues. Understanding and promoting productive interaction (pp.289-303). London, New York: Routledge.

Smith, H. \& Higgins, S. (2006). Opening classroom interaction: the importance of feedback. Cambridge Journal of Education, 36(4), 485-502.

Smit, K., de Brabander, C.J., \& Martens, R. L. (2014). Student-centred and teacher-centred learning environment in pre-vocational secondary education: Psychological needs and motivation. Scandinavian Journal of Educational Research, 58(6), 695-712. https://doi.org/10.1080/00313831.2013.821090

Tidemand, S. \& Nielsen, J. A. (2017). The role of socio-scientific issues in biology teaching: From the perspective of teachers. International Journal of Science Education, 39(1), 44-61. https://doi.org/10.1080 /09500693.2016.1264644.

Tsai, W. (2002). Social structure of "coopetition" within a multiunit organization: Coordination, competition, and intraorganizational knowledge sharing. Organization Science, 13(2), 179-190.

Ulu, H. (2017). Dördüncü sınıf fen ve teknoloji derslerinin diyalojik öğretim açısından analizi üzerine bir araştırma. Ana Dili Ĕgitimi Dergisi, 5(4), 608-626.

Uçak, E. (2014). Öğretmen adaylarının fen öğretiminde kullandıkları iletişimsel yaklaşım türleri. Unpublished doctoral dissertation. Pamukkale University, Denizli.

van der Veen, C., van Kruistum, C., \& Michaels, S. (2015). Productive classroom dialogue as an activity of shared thinking and communicating: A Commentary on Marsal, Mind, Culture, and Activity, 320-325. http://dx.doi.org/10.1080/10749039.2015.1071398

van Zee, E.H., Iwasyk, M., Kurose, A., Simpson, D., \& Wild, J. (2001). Student and teacher questioning during conversations about science. Journal of Research in Science Teaching, 38, 159-190. 
E, Uçak, A.S. Gencer, A. Seviş, \& S. Usta / Pamukkale University Journal of Education, 55, 294-323, 2022325

Yıldırım, A. ve Şimşek, H. (2006). Sosyal bilimlerde nitel araştırma yöntemleri (6.Baskı). Ankara: Seçkin Yayıncılık.

Yıldırım, L., Uçak, E. ve Savran-Gencer, A. (2021). Fen derslerinde sınıf içi konuşmalar üzerine sistematik bir derleme. Trakya Eğitim Dergisi, 11(3), 1148-1172.

Y1lmaz. Ş. (2017). Fen bilgisi öğretmenlerinin soru üretme hakkındaki muhakemeleri ve inanç sistemleri. Unpublished doctoral dissertation. Uludağ University, Bursa.

Zeidler, D. L., Sadler, T. D., Applebaum, S., \& Callahan, B. E. (2009). Advancing reflective judgment through socio-scientific issues. Journal of Research in Science Teaching, 46(1), 74-101. https://doi.org/10.1002/tea.20281. 